\title{
Towards a unified theory of plant photosynthesis and hydraulics
}

Jaideep Joshi ${ }^{1,2,}{ }^{*}$, Benjamin D. Stocker ${ }^{3,4}$, Florian Hofhansl ${ }^{1}$, Shuangxi Zhou ${ }^{5,6,7}$, Ulf Dieckmann ${ }^{1,8}$, and lain Colin Prentice ${ }^{5,9,10}$

${ }^{1}$ Evolution and Ecology Program, International Institute for Applied Systems Analysis, 2361 Laxenburg, Austria.

2 Divecha Centre for Climate Change, Indian Institute of Science, Bangalore 560012, India.

${ }^{3}$ Department of Environmental Systems Science, ETH, Universitätsstrasse 2, 8092 Zürich, Switzerland.

${ }^{4}$ Swiss Federal Institute for Forest, Snow and Landscape Research WSL, Birmensdorf, Switzerland.

${ }^{5}$ Department of Biological Sciences, Macquarie University, NSW 2109, Australia.

${ }^{6}$ CSIRO Agriculture and Food, Glen Osmond, SA, Australia.

${ }^{7}$ The New Zealand Institute for Plant and Food Research Limited, Hawke's Bay, New Zealand.

8 Department of Evolutionary Studies of Biosystems, The Graduate University for Advanced Studies (Sokendai), Hayama, Kanagawa 240-0193, Japan.

${ }^{9}$ Imperial College London, Department of Life Sciences, Silwood Park Campus, Ascot SL5 7PY, UK.

${ }^{10}$ Ministry of Education Key Laboratory for Earth System Modeling, Department of Earth System Science, Tsinghua University, Beijing 100084, China.

*Correspondence: joshi@iiasa.ac.at

\section{Abstract}

The global carbon and water cycles are strongly governed by the simultaneous diffusion of $\mathrm{CO}_{2}$ and water vapour through the leaves of terrestrial plants. These diffusive fluxes are controlled by plants' adaptations to balance carbon gains and hydraulic risks. We introduce a trait-based optimality theory that unifies the treatment of stomatal responses and biochemical acclimation of plants to changing environments. Tested with experimental data from eighteen species, our model successfully predicts the simultaneous decline in carbon assimilation rate, stomatal conductance, and photosynthetic capacity during progressive soil drought. It also correctly predicts the dependencies of gas exchange on atmospheric vapour pressure deficit, temperature, and $\mathrm{CO}_{2}$. Consistent with widely observed patterns, inferred trait values for the analysed species display a spectrum of stomatal strategies, a safety-efficiency trade-off, and a convergence towards low hydraulic safety margins. Our unifying theory opens new avenues for reliably modelling the interactive effects of drying soil and air and rising atmospheric $\mathrm{CO}_{2}$ on global photosynthesis and transpiration.

\section{Introduction}

The fundamental dilemma of plants following the C3 photosynthetic pathway is that when stomata, i.e., the tiny 'valves' on the surface of leaves, are opened to take in carbon dioxide $\left(\mathrm{CO}_{2}\right)$ for carbon assimilation, water is lost (transpired) through these stomata (Raschke et al., 1976). The plant's transpiration stream is maintained by negative water potentials (suction pressures) in transport vessels and leaf tissues. Withstanding negative water potentials requires adapted stem and leaf tissues or energy-intensive repair efforts, and extreme water potentials can lead to hydraulic failure (Brodribb et al., 2010; Brodribb and Cochard, 2009; Choat et al., 2018). Plants can avoid damaging water potentials by regulating their stomatal openings in response to declining water availability across the rooting zone or increasing vapour pressure deficit at the leaf surface. However, closing the stomata also leads to a decline in carbon assimilation, creating a tight coupling between carbon 
uptake and water loss. At the ecosystem level, this coupling of the carbon and water cycles affects the rates of gross primary production (GPP) and evapotranspiration in response to water stress. Globally, an increase in atmospheric $\mathrm{CO}_{2}$ coupled with increasing precipitation is expected to favour higher GPP (Keeling et al., 2017; Guerrieri et al., 2019). However, some regions are projected to face an increase in the frequency and intensity of drought, which would be expected to cause a decline of GPP (Zhou et al., 2019). This interplay of rising $\mathrm{CO}_{2}$ and water stress leads to large uncertainties in the projections of GPP and forest biomass (McDowell et al., 2020).

A plant's hydraulic machinery places key constraints on how much the plant can transpire, and consequently, on stomatal conductance. Considerable effort has gone into the development of stomatal control models with an explicit treatment of plant hydraulics (Damour et al., 2010; Y. Wang et al., 2020). These models have shown success in simulating short-term stomatal responses to drying soil and air at sub-daily and daily timescales (Anderegg et al., 2018; Venturas et al., 2018; Sabot et al., 2020; Eller et al., 2020) and are now being implemented in Earth System Models (Hickler et al., 2006; Bonan et al., 2014; Christoffersen et al., 2016; Kennedy et al., 2019). However, we lack robust predictions on how plant physiology acclimates to the development of soil-moisture drought at daily to weekly timescales and how such longer-term acclimation in turn affects stomatal sensitivity to short-term water stress. Specifically, we lack a unified theory to explain the widely observed patterns related to plant photosynthetic responses and hydraulic strategies (Box 1 ) in a parsimonious way.

The classic stomatal-optimization model by Cowan and Farquhar (1977) states that plants adjust their stomatal conductance to maximize the total carbon intake over time gained for a fixed amount of water loss, by assuming a constant unit cost of transpired water. This model implies that plants can save water for future use. However, it is now recognised that plants competitively consume available water. Therefore, an alternative approach conceives the costs of transpiration as arising from the risks of hydraulic failure and the structural and energetic expenditures for withstanding negative water potentials. Thus, many extensions of this classic model explicitly represent plant hydraulics and the associated costs (Wolf et al., 2016; Sperry et al., 2017; Bartlett et al., 2019). These models require an a priori specification of photosynthetic capacity, which then becomes an additional parameter to be fitted to enable accurate predictions of assimilation rates. By contrast, the least-costs optimization framework of Prentice et al. (2014) includes the costs of maintaining photosynthetic capacity, and using the photosynthetic coordination hypothesis (see below), predicts acclimated photosynthetic capacity from daytime light availability. Building upon this approach, Wang et al. (2017) explicitly optimize photosynthetic capacity (albeit using a separate optimization criterion) and have been successful in predicting the assimilation rates and leaf-internal $\mathrm{CO}_{2}$ concentrations across climatic gradients. However, their model lacks a representation of plant hydraulics, and thus cannot predict plant responses to soil drought, especially when soil and atmospheric water deficits are decoupled (Stocker et al., 2018, 2020). Here, we extend the foundational principles of Wang et al. (2017) with the principles of plant hydraulics and recast them in a profit-maximization framework. The proposed model simultaneously predicts the stomatal responses and biochemical acclimation (non-stomatal responses) of plants, thus unifying the functioning of a plant's machinery to utilize light and transport water into a single optimality framework. 


\section{Box 1. Widely observed patterns related to plant photosynthetic responses and hydraulic strategies, as targets for prediction.}

1. As soil moisture decreases, the first response of plants to reduce water stress is to reduce their stomatal opening. As stomata begin to close, transpiration declines, but so does carbon assimilation. Thus, assimilation and transpiration rates decline with decreasing soil moisture (Stocker et al., 2018).

2. As assimilation declines, maintaining photosynthetic capacity no longer pays off. Therefore, plant photosynthetic capacity declines with decreasing soil moisture in the short-term (Kanechi et al., 1996; Salmon et al., 2020). However, given sufficient time to acclimate, plants shed their leaves, reducing transpiration demand, and allowing assimilation to recover. Thus, photosynthetic capacity recovers in the long-term as plants acclimate through leaf-shedding (Zhou et al., 2016).

3. Across species, the leaf internal-to-external $\mathrm{CO}_{2}$ ratio $c_{i}: c_{a}$, or $\chi$, varies with growing-season-mean vapour pressure deficit $D$ such that $\operatorname{logit}(\chi)$ is proportional to $\log (D)$. The slope of this $\operatorname{logit}(\chi) \sim \log D$ relationship is widely believed to be -0.5 , but a recent study conducted across a large climatic gradient in Australia has reported values of $-0.76 \pm 0.15$ (Dong et al., 2020).

4. As soil dries, xylem water potentials become increasingly negative. Extreme water potentials create embolisms in the xylem, which have been linked to increased risks of mortality due to hydraulic failure. To avoid these risks, Plants close their stomata before the onset of substantial xylem embolism (Brodribb et al., 2003; Martin-StPaul et al., 2017; Scoffoni et al., 2017; Choat et al., 2018);

5. To maximize carbon assimilation, plants tend to keep the stomata open for as long as possible, often close to the point of hydraulic failure. Thus plants across species operate at extremely low hydraulic safety margins (Choat et al., 2012).

6. Plants span a spectrum of hydraulic strategies (Klein, 2014; Papastefanou et al., 2020), from isohydric (drought-avoiding), through isohydrodynamic (maintaining a constant soil-to-leaf water potential difference), to anisohydric (droughttolerating).

The principles and hypotheses underlying our model can be stated in general terms as follows (Fig. 1 ; their concrete mathematical formulations are presented in the next section):

(1) Water-balance principle. A plant must maintain a continuous transpiration stream across its entire hydraulic pathway (from roots through stem and leaves) to prevent xylem embolism and leaf desiccation. Therefore, for a given atmospheric vapour pressure deficit (VPD), plants adjust their stomatal conductance $g_{\mathrm{s}}$ such that the atmospheric demand for transpiration is matched by the supply of water from the soil (Sperry and Love, 2015). Since the supply is dependent on the soil-toleaf water-potential difference $\Delta \psi$ and the hydraulic properties of the transpiration pathway, this principle predicts $\Delta \psi$ as a function of $g_{\mathrm{s}}$ and is widely used in stomatal models that explicitly represent water transport. We use the term 'principle' rather than 'hypothesis' for this assumption to indicate its rooting in basic physical laws. 
(2) Photosynthetic coordination hypothesis. Photosynthetic carbon assimilation is limited by a plant's capacity for carboxylation $V_{\mathrm{cmax}}$ and light availability $I_{\mathrm{abs}}$, which determine the rates of biochemical and photochemical reactions governing $\mathrm{CO}_{2}$ fixation (Farquhar et al., 1980). In general, the rate of photosynthesis is the minimum of the carboxylation-limited rate $A_{\mathrm{c}}$ and the light-limited rate $A_{\mathrm{j}}$. The light-limited rate is further modulated by the plant's electron transport capacity $J_{\text {max }}$. Since the carboxylation and electron-transport capacities are costly to maintain, they are hypothesized to acclimate to typical daytime conditions on a weekly timescale, such that the two photosynthetic rates are coordinated, i.e., $A_{\mathrm{c}}=A_{\mathrm{j}}$ (Chen et al., 1993; Maire et al., 2012).

(3) Profit-maximization hypothesis. We posit that on a weekly timescale, plants simultaneously optimize their photosynthetic capacity and stomatal conductance to maximize net assimilation (profit), after accounting for costs of maintaining the photosynthetic capacity and the risks of hydraulic failure. Parameters which scale these costs, $\alpha$ and $\gamma$ respectively, are the only two latent (i.e., not directly observable) parameters in our model, and are henceforth called 'unit costs'.

(4) Leaf-hydraulic efficiency hypothesis. We hypothesize that under normal operating conditions, plants fully utilize the leaf hydraulic machinery (by maintaining sufficiently negative leaf water potentials) without desiccating the leaves (by preventing leaf water potentials from becoming too negative). This implies that $\Delta \psi$ scales with the hydraulic capacity of the leaf, measured by the water potential at which $50 \%$ leaf conductivity is lost, $\psi_{50}$. This is analogous to how plants allow seasonalminimum leaf water potentials $\psi_{\min }$ to fall close to their xylem- $\psi_{50}$ so as to fully utilize the xylem hydraulic machinery without causing hydraulic failure under moderately water-stressed conditions (Choat et al., 2012). Since the unit hydraulic cost $\gamma$, together with the plant's hydraulic traits (in particular, the leaf conductivity $K$ ), determine the magnitude of the leaf water potentials that the plant maintains, this hypothesis constrains $K$ and $\gamma$ for any value of $\Delta \psi$. In a given environment, different values of $\Delta \psi$ can lead to the same stomatal conductance for suitable combinations of $K$ and $\gamma$, with some combinations potentially performing better than others in the long term. The question then arises, how should plants adapt their traits to maximize long-term growth and survival? The natural way to answer this question would be adopt a whole-plant, whole-lifecycle perspective (Fig. S9 shows a corresponding potential plant-level optimality criterion). However, in the present work, we use a simple heuristic specification of $\Delta \psi$ as equal to $\psi_{50}$ under average nonstressed conditions. This has the advantage of improving model performance while reducing the risks of overfitting. 


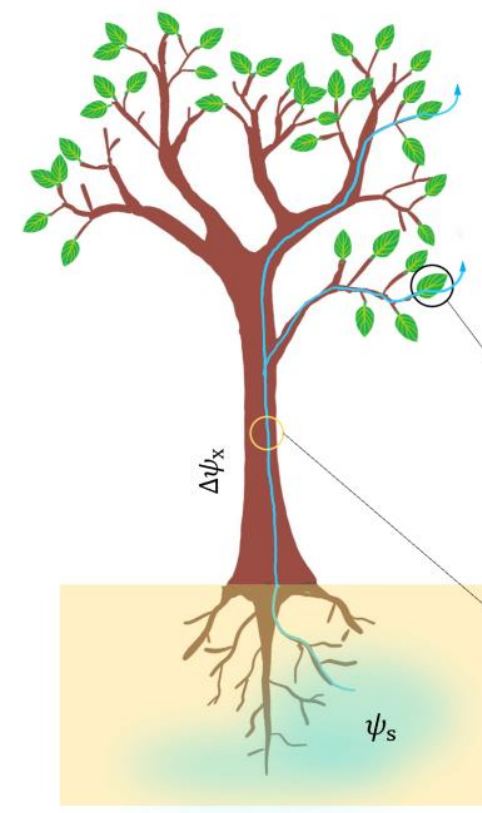

A

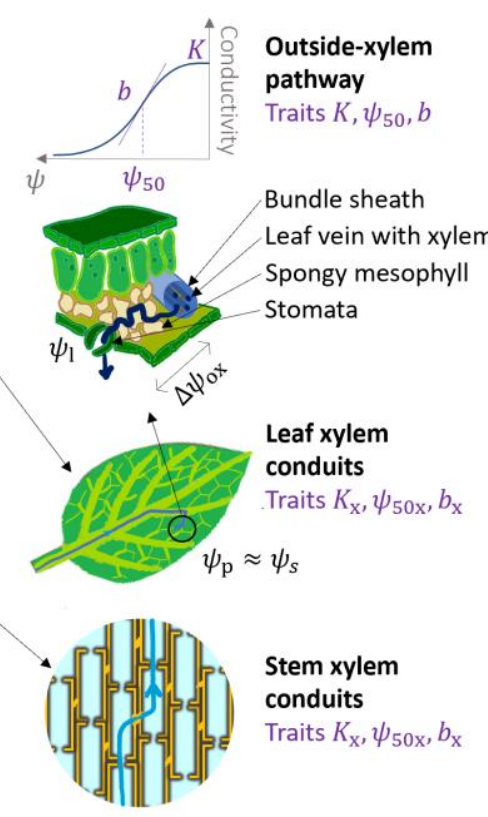

Stem xylem conduits (1)

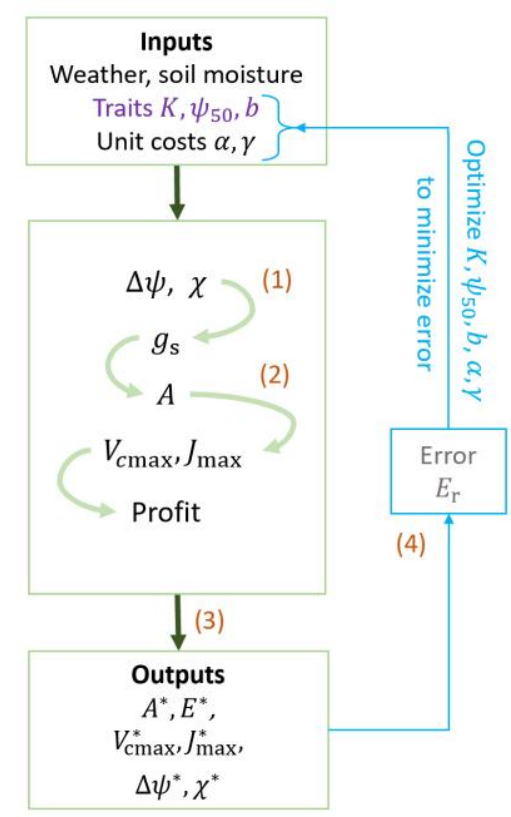

B

Fig. 1. Schematic representation of model, first principles, and notations. (A) Water-transport pathway. Water flows from the soil via roots into the stem xylem conduits, from where it enters the xylem in the leaf veins. After exiting the xylem, it passes through the bundle sheath and spongy mesophyll cells before reaching the stomata, from where it diffuses out in gaseous form. This watertransport pathway can thus be divided into two segments: the xylem segment and the outside-xylem segment. Purple labels indicate three hydraulic traits that determine the conductivities along these segments as functions of the water potential $\psi$ : the maximum conductivity $K$, the water potential $\psi_{50}$ at which $50 \%$ conductivity is lost, and the rate $b$ of conductivity loss. Water potentials are shown at various points along the pathway, $\psi_{\mathrm{s}}$ in soil, $\psi_{\mathrm{p}}$ at the end of the xylem segment, and $\psi_{\mathrm{l}}$ at the end of the outside-xylem segment, i.e., near the stomata. The soil-to-leaf water potential difference $\Delta \psi=\psi_{\mathrm{s}}-\psi_{\mathrm{l}}$ thus comprises of the pressure drops $\Delta \psi_{\mathrm{x}}=\psi_{s}-\psi_{\mathrm{p}}$ and $\Delta \psi_{\mathrm{ox}}=\psi_{\mathrm{p}}-\psi_{l}$ along the xylem and outside-xylem segments, respectively. (B) Model-calibration pathway. We assume that the leaf is the hydraulic bottleneck of the plant, and therefore focus on the pressure drop $\Delta \psi_{\text {ox }}$ along the outside-xylem segment (this assumption is more formally justified in the text and $\mathrm{SI}$ ). The model thus takes as inputs the three outside-xylem hydraulic traits, together with two cost parameters, namely the unit costs of photosynthetic and hydraulic capacities, $\alpha$ and $\gamma$, respectively. It predicts as outputs the stomatal conductance $g_{s}$, optimal assimilation rate $A^{*}$, transpiration $E^{*}$, acclimated photosynthetic capacities $V_{\text {cmax }}^{*}$ and $J_{\max }^{*}$, soil-to-leaf water potential difference $\Delta \psi^{*}$, and leaf internal-to-external $\mathrm{CO}_{2}$ ratio $\chi^{*}$. Each variable is calculated as a function of $\Delta \psi$ and $\chi$, as shown by the four curved arrows, from which the optimal combination $\left(\Delta \psi^{*}, \chi^{*}\right)$ is calculated by maximizing profit according to Eq. 1 . Blue arrows and boxes indicate the process through which the best-fit traits and unit costs for each species are calculated by minimizing the model error. Orange labels indicate the four principles and hypotheses underlying the model, shown next to the processes they affect.

\section{Model summary}

We assume that plants independently control their stomatal conductance $g_{\mathrm{s}}$ and electron-transport capacity $J_{\max }$ to maximize net profit from assimilation $F$. All quantities can be expressed in terms of $g_{\mathrm{s}}$ and $J_{\text {max }}$, or equivalently and more simply, in terms of the leaf internal-to-external $\mathrm{CO}_{2}$ ratio $\chi$ and the soil-leaf water potential difference $\Delta \psi$ (see Supporting Information for the full derivation), 


$$
F(\chi, \Delta \psi)=A(\chi, \Delta \psi)-\alpha J_{\max }(\chi, \Delta \psi)-\gamma \Delta \psi^{2} .
$$

We find the optimal solution $\left(\chi^{*}, \Delta \psi^{*}\right)$ semi-analytically: we calculate the derivatives of $F$ with respect to $\chi$ and $\Delta \psi$ analytically, and set them to zero using a numerical root-finding algorithm.

Assimilation $A$ is calculated from the standard biochemical model of photosynthesis (Farquhar et al., 1980) (Eq. 5 in Methods), with $J_{\max }$ and $V_{\text {cmax }}$ obtained from $g_{\mathrm{s}}$ and $\chi$ using the coordination hypothesis (Fig. 1B). Temperature responses of photosynthesis parameters, such as the MichaelisMenten coefficient and the light compensation point, are modelled according to Stocker et al. (2020).

We model water transport using Darcy's law applied to small cross-sections of the hydraulic pathway (SI-Section 1.1.2.1). Inside the plant, water first flows through the roots, then through the xylem in the stem and in leaf veins. After exiting the vein, it flows outside the xylem through the bundle sheath and spongy mesophyll cells, until it evaporates from the stomatal cell-walls and diffuses out (Buckley et al., 2015) (Fig. 1A). The hydraulic pathway thus broadly consists of the xylem and outside-xylem segments. Conductivities of these segments decline as water potentials become more negative. Therefore, the flow of water through each segment is characterized by (at least) three readily measurable hydraulic traits: (i) maximum conductivity (accounting for path-length) $K$, (ii) water potential that causes $50 \%$ loss of conductivity $\psi_{50}$, and (iii) a trait indicating the rate at which conductivity is lost $b$. In principle, our model of water transport can explicitly represent both segments (Eq. 3 in Methods). However, there is increasing evidence that the outside-xylem segment forms the hydraulic bottleneck of the plant (Sack and Holbrook, 2006; Scoffoni et al., 2017). Based on this evidence, we neglect the potential drop along the xylem, which allows us to eliminate xylem traits (Eq. 4 in Methods). In this approximate treatment, the hydraulic pathway is 'unsegmented' and our water-transport model is mathematically identical to the one described in Sperry et al. (2017), but with a different interpretation of the corresponding hydraulic traits.

The hydraulic costs could consist of, (i) the construction and respiration costs of the stem and leaves, (ii) the costs of maintaining osmotic potential in the leaves (which is not explicitly modelled here), and (iii) the prospective costs of hydraulic failure. While it may be possible to derive expressions for (i) and (ii) with mechanistic arguments, (iii) is more difficult to quantify. Instead, we have taken a phenomenological approach, and used the expression $\Delta \psi^{2}$ after assessing several alternative cost expressions including $\psi_{L}, \Delta \psi, \Delta \psi^{2}$, and PLC (percent loss of hydraulic conductivity). A cost expression which is quadratic in $\Delta \psi$ has also been adopted previously (Wolf et al., 2016).

We test the predictions of our model with published data from soil drought experiments conducted with 18 plant species spanning diverse plant functional types (Table 1) (Zhou et al., 2013). In these experiments, plants were grown in greenhouses under controlled conditions similar to their native habitats, and subjected to progressive soil-drought over a span of $2-4$ months. The progression of drought was slow enough to allow photosynthetic capacity to acclimate. Values of $A$ and $g_{\mathrm{s}}$ were reported for different values of pre-dawn leaf water potentials, which are indicative of the soil water potential in the plant's rooting zone.

Since hydraulic traits of the outside-xylem pathways are not readily available, we treat them as model parameters and calibrate them along with the two cost parameters. For each species we calibrate five parameters $\left(\alpha, \gamma, \psi_{50}, b, K\right)$ by minimizing the sum of squared errors $\left(E_{\mathrm{r}}\right)$ between predicted and observed values of $A, g_{\mathrm{s}}$, and $\chi$. Parameter estimation is additionally constrained due to the leaf-hydraulic efficiency hypothesis. Due to paucity of data on leaf $\psi_{50}$, it is not possible to 
concretely specify to what extent plants can tolerate leaf-conductivity loss. For simplicity, we tentatively assume that under non-water stressed conditions $\left(\psi_{\mathrm{s}}>\psi_{50}\right), \Delta \psi \approx \psi_{50}$ (i.e., the plant tolerates on average about $50 \%$ loss of leaf conductivity). To implement this hypothesis, we modify the error function $E_{\mathrm{r}}$ to include deviations of $\Delta \psi$ from an 'expected' value $\left(\psi_{50}\right)$ (Eq. 8 in Methods). This additional constraint not only improves the predictions of $\Delta \psi$, but also helps reduce overfitting of the model. For each species, we evaluate model performance using 5 -fold cross-validation (or leave-one-out cross-validation where data points are limited).

In our dataset, midday leaf water potentials were reported for two species. We do not use these data for parameter estimation, and instead set them aside to independently test the model. We further expand this testing data using typical values reported in the literature for $\Delta \psi$. When using such literature-derived values, we only include species for which three or more replicates are available, so that the confounding effects of a mismatch in environmental conditions are minimized. We also compare fitted trait values with different but physiologically related traits obtained from the literature.

\begin{tabular}{|c|c|c|c|c|c|c|c|c|c|c|}
\hline \multirow[t]{2}{*}{ Species } & \multirow[t]{2}{*}{$\begin{array}{l}\text { Plant functional } \\
\text { type }\end{array}$} & \multirow{2}{*}{$\begin{array}{c}\text { Ref } \\
(A- \\
\left.g_{s}\right)\end{array}$} & \multicolumn{5}{|c|}{ Fitted traits and unit costs } & \multicolumn{2}{|c|}{$\begin{array}{l}\text { Data from } \\
\text { literature }\end{array}$} & \multirow[t]{2}{*}{$\begin{array}{l}\text { Ref } \\
\left(\psi_{50 X}\right)\end{array}$} \\
\hline & & & $\begin{array}{c}K \\
\left(\times 10^{-16}\right. \\
\mathrm{m})\end{array}$ & $\begin{array}{c}\psi_{50} \\
(\mathrm{MPa})\end{array}$ & $b$ & $\alpha$ & $\gamma$ & $\begin{array}{c}\tilde{\psi}_{50 x} \\
(\mathrm{MPa})\end{array}$ & $\begin{array}{c}\text { STA } \\
\left(\mathrm{m}^{2} \mathrm{~kg}^{-1}\right)\end{array}$ & \\
\hline Cedrus atlantica & Gymnosperm & G88 & 0.08 & -2.24 & 2.07 & 0.10 & 0.02 & -4.98 & 8.17 & MS \\
\hline Pseudotzuga menziesii & Gymnosperm & G88 & 0.14 & -1.72 & 1.67 & 0.10 & 0.04 & -4.82 & & MS \\
\hline Glycine max & Herb & L5 & 2.52 & -0.52 & 1.01 & 0.08 & 3.47 & & 30.70 & \\
\hline Helianthus annuus & Herb & T8 & 3.69 & -0.75 & 2.31 & 0.03 & 0.34 & -3.05 & 19.09 & MS \\
\hline Broussonetia papyrifera & M. Angiosperm & L10 & 3.78 & -0.55 & 1.11 & 0.10 & 1.39 & -0.49 & 27.21 & TRY \\
\hline Platycarya longipes & M. Angiosperm & L10 & 3.01 & -0.51 & 0.77 & 0.09 & 2.31 & -1.50 & 13.77 & BA \\
\hline Pteroceltis tatarinowii & M. Angiosperm & L10 & 1.19 & -1.05 & 1.16 & 0.11 & 0.26 & -0.96 & & BA \\
\hline Allocasuarina luehmannii & S. Angiosperm & PB & 0.84 & -0.96 & 1.58 & 0.12 & 0.58 & & 4.64 & \\
\hline Cinnamomum bodinieri & S. Angiosperm & L10 & 2.05 & -0.83 & 1.25 & 0.11 & 0.41 & & & \\
\hline Eucalyptus pilularis & S. Angiosperm & K16 & 1.16 & -0.67 & 1.70 & 0.05 & 3.36 & & 1.11 & \\
\hline Eucalyptus populnea & S. Angiosperm & K16 & 0.72 & -1.35 & 0.98 & 0.06 & 0.95 & & 5.38 & \\
\hline Olea europaea v. Chemlali & S. Angiosperm & E8 & 1.30 & -1.41 & 1.33 & 0.07 & 0.53 & -9.73 & 5.78 & MS \\
\hline Olea europaea v. Meski & S. Angiosperm & E8 & 2.24 & -0.79 & 0.57 & 0.11 & 1.08 & -7.95 & 5.78 & $M$ \\
\hline Quercus coccifera & S. Angiosperm & PP9 & 0.61 & -1.52 & 1.35 & 0.08 & 0.31 & -6.87 & 4.93 & $M$ \\
\hline Quercus ilex & S. Angiosperm & PP9 & 1.26 & -1.25 & 0.83 & 0.11 & 0.26 & -6.90 & 6.89 & MS \\
\hline Quercus suber & S. Angiosperm & PP9 & 2.79 & -0.96 & 0.76 & 0.10 & 0.51 & -5.20 & 10.78 & MS \\
\hline Ficus tikoua & Shrub & L11 & 2.96 & -0.85 & 1.24 & 0.12 & 0.31 & -4.81 & & MS \\
\hline Rosa cymosa Trattinnick & Shrub & L10 & 1.28 & -1.10 & 1.17 & 0.09 & 0.65 & & 16.63 & \\
\hline
\end{tabular}

Table 1. List of species used for testing our model. For each species, data on gas exchange for different values of predawn water potential were obtained from Zhou et al. (2013), who in turn compiled them from the sources listed in the column 'Ref $\left(A-g_{s}\right)$ '. Three hydraulic traits and two cost parameters were fitted using this data, and the fitted values are listed here. Data on xylem vulnerability $\left(\tilde{\psi}_{50 X}\right)$ and were compiled from the sources mentioned in column 'Ref $\left(\psi_{50 X}\right)$ '. Data on Specific Leaf Area (SLA) was obtained from the TRY database (Kattge et al. 2011).

G88 - (Grieu et al., 1988) MS - (Martin-StPaul et al., 2017) TRY - (Kattge et al., 2011) BA (Bartlett et al., 2019) M - (Manzoni et al., 2014) PB - (Posch and Bennett, 2009) L5 - (Liu et al., 2005) L10 - (Liu et al., 2010) L11 - (Liu et al., 2011) E8 - (Ennajeh et al., 2008) K16 - (Kelly et al., 2016) PP9 - (Peguero-Pina et al., 2009) T8 - (Tezara et al., 2008) 


\section{Results}
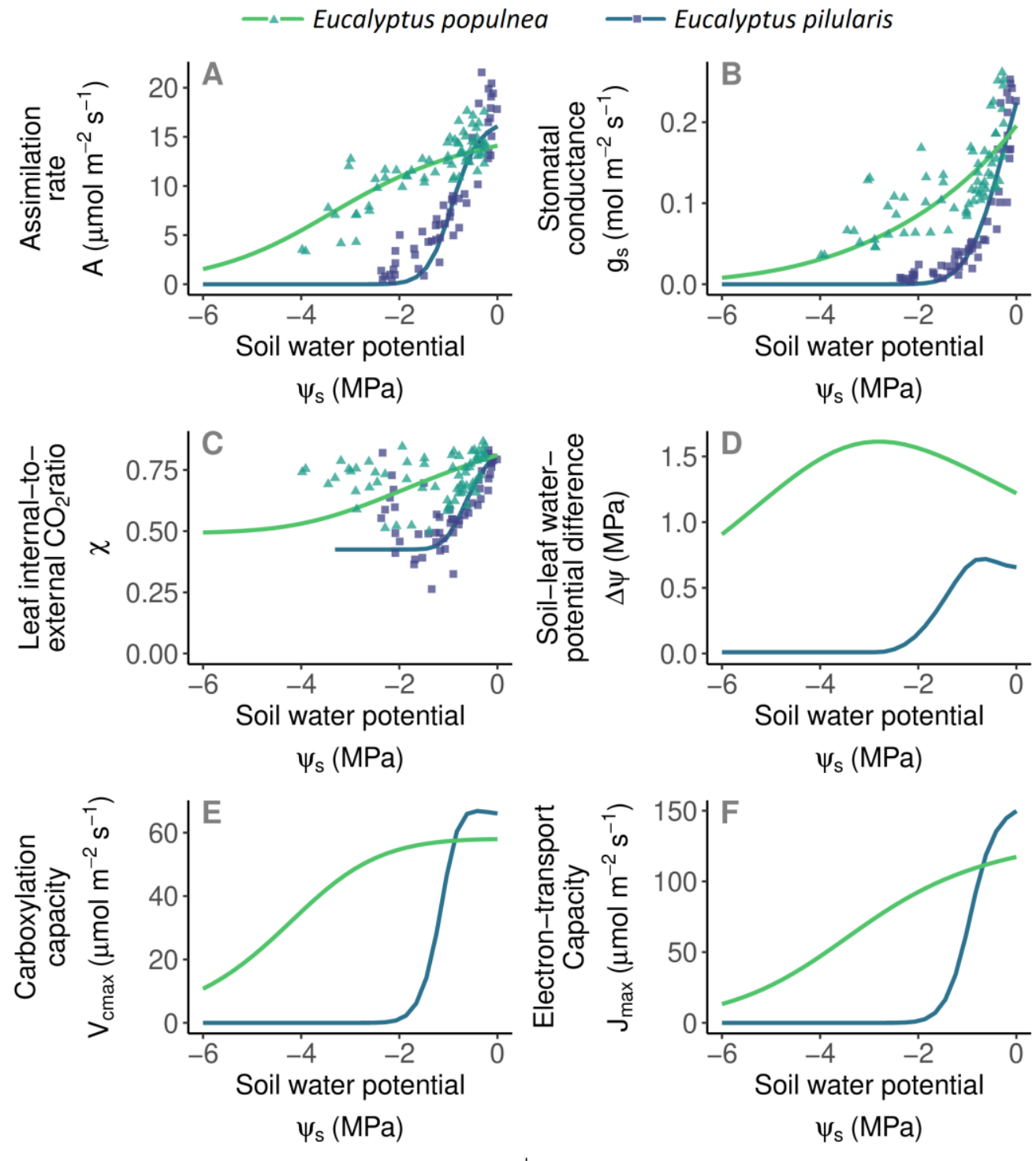

Fig. 2. Predicted responses of two Eucalyptus species from contrasting climates to progressive soil dry-down closely match observations. The predicted (lines) and observed (points) responses of (A) assimilation rate $A,(\mathrm{~B})$ stomatal conductance $g_{s},(\mathrm{C})$ leaf-internal to external $\mathrm{CO}_{2}$ ratio $\chi,(\mathrm{D})$ soil-toleaf water potential difference $\Delta \psi,(\mathrm{E})$ carboxylation capacity $V_{\text {cmax }}$, and (F) electron transport capacity $J_{\text {max }}$, to decreasing soil water potential $\left(\psi_{s}\right.$, measured as pre-dawn leaf water potential), for two evergreen Eucalyptus species. Blue lines and squares represent Eucalyptus pilularis, and green lines and triangles represent Eucalyptus populnea. The two species are found in contrasting climates: Eucalyptus pilularis occupies warm and humid coastal areas in eastern Australia, whereas Eucalyptus populnea occupies semi-arid interior regions of eastern Australia. Thick lines represent the full model with multivariate optimization of $J_{\max }$ and $\Delta \psi$, whereas thin lines represent a model where only $\Delta \psi$ was optimized and $J_{\max }$ was treated as a constant, and fitted along with other parameters. Similar responses for all 18 species can be found in the Supplementary Information (Fig. S1-Fig. S3). 


\subsection{Our model correctly predicts the simultaneous decline in gas exchange and photosynthetic capacity under progressive drought}

For each species, our model successfully predicts the stomatal and photosynthetic responses of plants to developing water stress (Fig. 2, Fig. S1-Fig. S3). Specifically, the functional forms of the decline in stomatal conductance $\left(g_{\mathrm{s}}\right.$, typically exponential-like), assimilation rate ( $A$, typically $\mathrm{S}$ shaped), and the $c_{\mathrm{i}}: c_{\mathrm{a}}$ ratio $(\chi)$ closely resemble those observed in the drought experiments. Our model predicts a decline in photosynthetic capacity with decreasing soil moisture, as has been previously reported (Kanechi et al., 1996; Salmon et al., 2020). Although we do not have direct measurements of photosynthetic capacity in the current dataset, simultaneous changes in photosynthetic capacity and stomatal conductance are expressed through the $c_{\mathrm{i}}: c_{\mathrm{a}}$ ratio, which thus provides a validation for this prediction. Across all 18 species, our model predictions of $A, g_{\mathrm{s}}$, and $\chi$ closely match the observed responses (Fig. 3A-C). Since observed values of the soil-to-leaf water potential difference $(\Delta \psi)$ were not used for parameter estimation, the match between predicted and observed $\Delta \psi$ provides independent validation of the model's assumptions, particularly, the leafhydraulic efficiency hypothesis (Fig. 3D). For each species, we report the (temporal) model generalizability using cross-validation (Table S1).

A Assimilation rate, A $\left(\mu \mathrm{mol} \mathrm{m} \mathrm{m}^{-2} \mathrm{~s}^{-1}\right)$

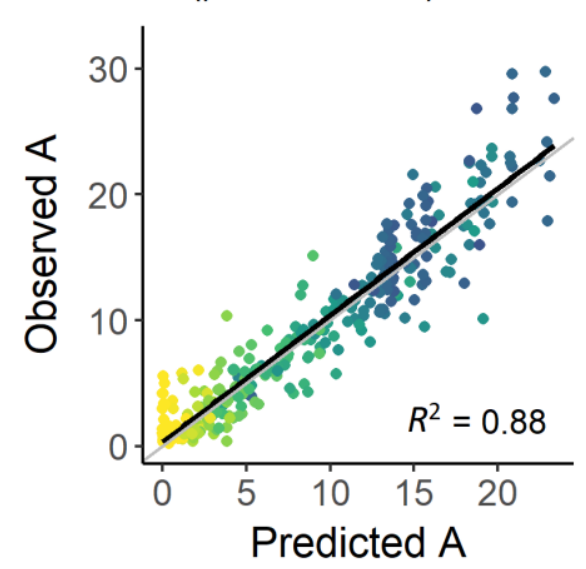

C Leaf internal-toambient $\mathrm{CO}_{2}$ ratio, $\chi$

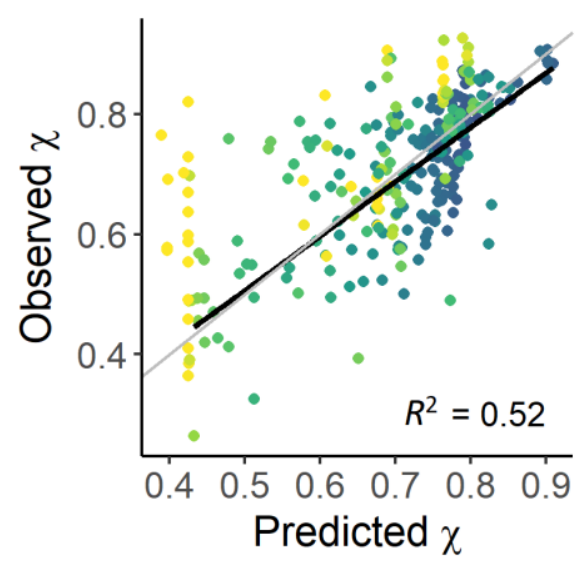

B Stomatal conductance,

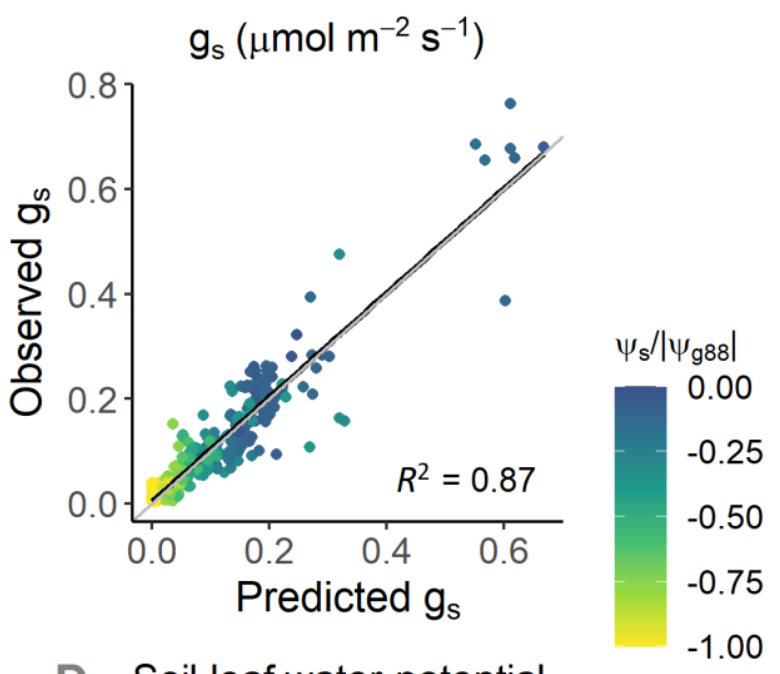

D Soil-leaf water-potential difference, $\Delta \psi(\mathrm{MPa})$

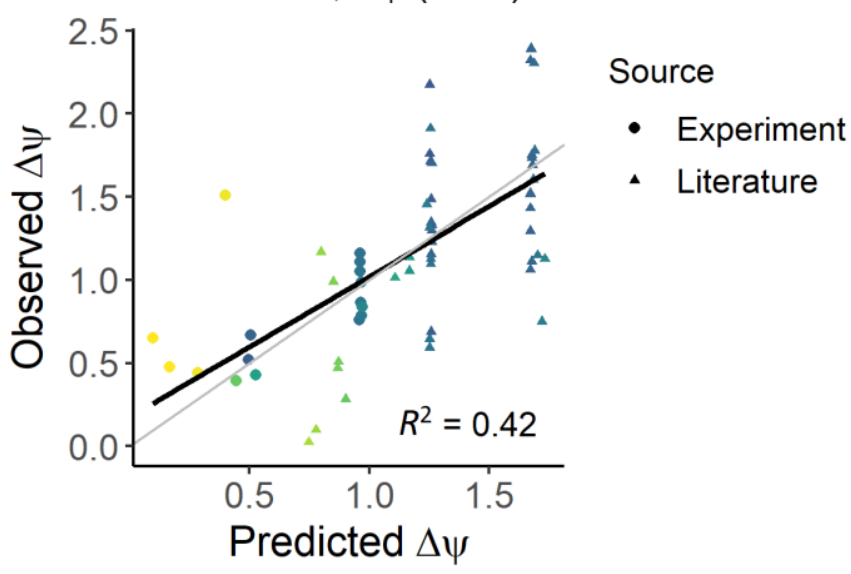

Fig. 3. Predicted and observed gas-exchange rates and water relations for 18 species. (A-C) Pooled data from all 18 species comparing assimilation rate $A$, stomatal conductance $g_{\mathrm{s}}$, and $c_{\mathrm{i}}: c_{\mathrm{a}}$ ratio $\chi$, 
for different values of soil water potential. (D) Predicted values of $\Delta \psi$ compared with observations for (i) two species (Allocasuarina luehmannii and Glycine max) for which midday water potentials were reported in the same experiments, and thus measured under the same environmental conditions as the gas exchange rates (circles), and (ii) broad values reported in the literature (Papastefanou et al. 2020) for two species (Pseudotzuga menziesii and Quercus ilex; triangles). Since environmental conditions may differ between gas-exchange and leaf water measurements for such species, we only included those species for which data was available from multiple sources. Colours are mapped to soil water potential normalized by the absolute value of the water potential at $88 \%$ stomatal closure $\left(\psi_{\mathrm{g} 88}\right)$ of the species; thus yellow points represent water potentials at or beyond stomatal closure. Black lines are regression lines, whereas grey lines are 1:1 lines. In panel (C), we removed points with $\psi_{\mathrm{s}}<\psi_{\mathrm{g} 88}$ (yellow points) before calculating the regression line, since there is a known bias in predictions of $\chi$ beyond stomatal closure (see Discussion). $R^{2}$ values were calculated on all data.

\subsection{Our model correctly predicts the photosynthetic responses to vapour pressure deficit and other atmospheric variables}

A widely used mathematical formulation describing the relationship between the leaf $c_{\mathrm{i}}: c_{\mathrm{a}}$ ratio $(\chi)$ and vapour pressure deficit as a fraction of atmospheric pressure $(D)$ is $\chi=\xi /(\xi+\sqrt{D})$, where $\xi$ is a constant (Medlyn et al., 2011). This implies that the relationship between $\operatorname{logit}(\chi)$ and $\log (D)$ is a straight line with slope -0.5 , a value often targeted for modelling (Wolf et al., 2016; Wang et al., 2017). However, analysing data on hundreds of species along aridity gradients, Dong et al. (2020) have reported slope values of $-0.76 \pm 0.15$, with remarkable consistency across species. Our model shows a close match with these observations. For each species, we calculate the slope by varying $D$ between $5-5000$ Pa while keeping other environmental parameters constant (at values reported in the experiments, and $\psi_{\mathrm{s}}=0$ ) and with fitted trait values according to Table 1 . Our model predicts a linear relationship between $\operatorname{logit}(\chi)$ and $\log (D)$, with slope values of $-0.72 \pm 0.02$ for the species in our dataset (Fig. 4A). We also find that this slope is correlated with the slope of the hydraulic vulnerability curve $b$, with more negative values for species with sharper vulnerability curves (Fig. 4B). This match between predicted and observed slope values also acts as a further independent test of our model.

Since our work builds upon the principles of Wang et al. (2017), it inherits their ability to accurately capture (Lavergne et al., 2020) the dependencies of $\chi, A$, and $V_{\text {cmax }}$ on temperature, vapour pressure deficit, elevation, atmospheric $\mathrm{CO}_{2}$, and light intensity (Fig. S4). 


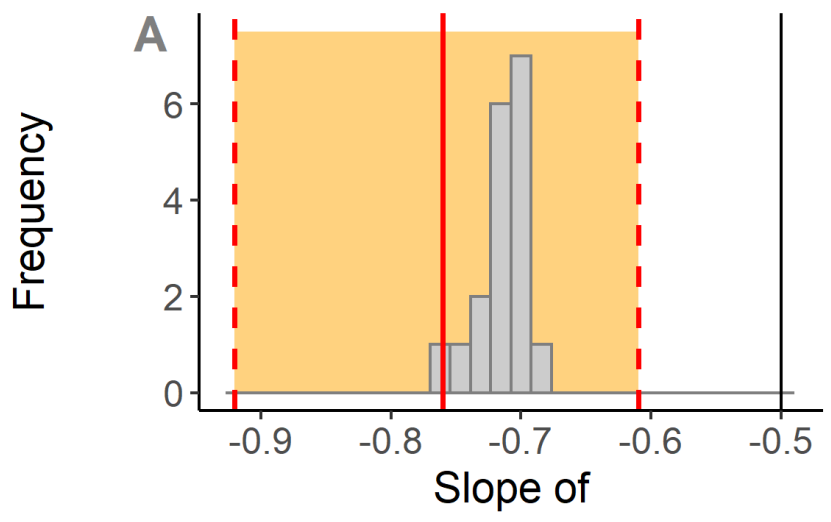

$\operatorname{logit}(\chi) \sim \log (D)$

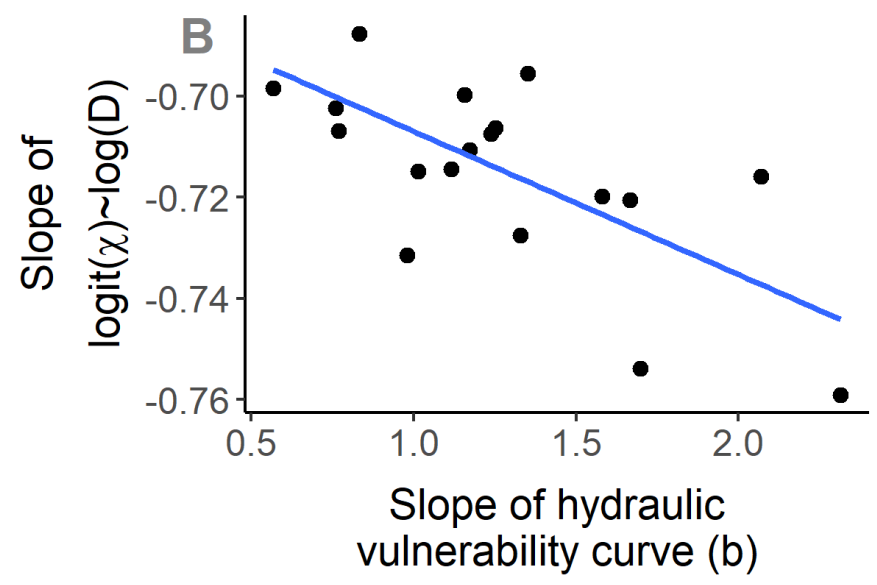

Fig. 4. Our model correctly predicts the response of $\chi$ to vapour pressure deficit. (A) The distribution of the slopes of the $\operatorname{logit}(\chi)$ vs. $\log (D)$ relationships predicted by our model (grey bars) is well within the range reported by Dong et al (2020) (mean and confidence interval as reported by them shown by red lines and orange region respectively) and significantly different from -0.5 (black line): a one-sample t-test shows predicted mean $=-0.715$ and $95 \%$ confidence interval $=$ $[-0.72,-0.71]$. For the species in our dataset, the slope values were calculated by varying vapour pressure deficit between $5-5000 \mathrm{~Pa}$, with other environmental variables held fixed (as per the reported experimental conditions) and trait values according to Table 1. (B) This slope is correlated with the slope of the hydraulic vulnerability curve $(b)$, with more negative slopes observed for species with steeper vulnerability curves (drought avoiders).

\subsection{Fitted traits reveal a spectrum of hydraulic strategies consistent with empirical observations}

Hydraulic traits and cost parameters were calibrated separately for the 18 plant species in our dataset. By explicitly resolving the hydraulic mechanisms and the links between functional traits, the emerging relationships among fitted traits across species enable us to test the model at an even deeper level, and to provide a theoretical grounding to several general observations related to plant hydraulic strategies. We first demonstrate the emergent relationships between various modelpredicted variables and fitted parameters, which allow us to recover trade-offs and hydraulic strategies (Fig. 5A,B,D,E). Then, we compare some of the fitted parameters with other traits obtained from literature, which allows us to relate the model principles to widely established empirical observations (Fig. 5C,F). 
First, a strong correlation emerges between the water potential at $50 \%$ loss of leaf conductivity $\left(\psi_{50}\right)$ and the water potential at $12 \%$ stomatal closure $\left(\psi_{\mathrm{g} 12}\right.$, calculated from the predicted response of $g_{\mathrm{s}}$ to soil water potential) (Fig. $5 \mathrm{~A} ; r=1.00$ ). This suggests that loss of leaf conductivity could be the trigger for initiating stomatal closure. Similarly, a strong correlation emerges between the water potentials at $88 \%$ loss of leaf conductivity $\left(\psi_{88}\right)$ and $88 \%$ stomatal closure $\left(\psi_{\text {g88 }}\right)$ (Fig. S7, $r=0.98$ ). This implies that a near-complete loss of leaf conductivity correlates with near-complete stomatal closure. Second, the unit cost of hydraulics $(\gamma)$ is strongly correlated with $\psi_{50}$ (Fig. 5D), which is a direct consequence of the leaf-hydraulic efficiency hypothesis, and can be understood as an evolutionary adaptation to maximize the utilization of the leaf hydraulic machinery. Third, although a trade-off between safety $\left(\psi_{50}\right)$ and efficiency $(K)$ is expected, studies have found no correlation between xylem vulnerability $\left(\psi_{50 \mathrm{x}}\right)$ and xylem conductivity, triggering various alternative hypotheses as to why such a trade-off may not exist (Gleason et al., 2016; Santiago et al., 2018). However, it is clearly revealed within our (fitted) traits, where safety and efficiency correspond to the leaf (outside-xylem pathways) (Fig. 5B), suggesting that xylem may not be the appropriate place to look for this trade-off. Indeed, the correlation between $K$ and $\psi_{50}$ disappears if we use the observed xylem vulnerability values instead (Fig. S7). Fourth, we find a weak but significant negative correlation between the photosynthetic and (scaled) hydraulic costs (Fig. 5E). This might reflect a trade-off in resource allocation, implying that plants may have to trade-off investments between the photosynthetic and hydraulic machineries.

Fifth, consistent with widely reported empirical evidence (Choat et al., 2012), values of xylem vulnerability obtained from the literature $\left(\tilde{\psi}_{50 \mathrm{x}}\right)$ are correlated with and generally more negative than the model-predicted values of $\psi_{\mathrm{g} 88}$ (Fig. 5C). This means that plants close their stomata before the onset of substantial xylem embolism (Brodribb et al., 2003; Martin-StPaul et al., 2017; Scoffoni et al., 2017). This is likely an adaptation to prevent xylem embolism, which is strongly linked to plant mortality during drought (Choat et al., 2018). While avoiding xylem embolism, the plant must also be able to fully utilize the available range of xylem water potentials - the hydraulic safety margin $\left(\psi_{50 \mathrm{X}}-\psi_{\mathrm{min}}\right.$, treating $\psi_{\mathrm{g} 88}$ as a proxy for $\left.\psi_{\mathrm{min}}\right)$ is thus narrow on average (low difference between trendline and 1:1 line), and increases slightly with more negative $\psi_{\text {g88 }}$ (Meinzer et al., 2009)(Fig. 5B). This is consistent with the observed global convergence towards low hydraulic safety margins (Choat et al., 2012).

Sixth, a correlation between model-derived leaf conductivity and observed mean values of specific leaf area ( SLA) of respective species implies that the leaf-economic spectrum is linked to plant hydraulics (Méndez-Alonzo et al., 2012; Nardini et al., 2012; Flexas et al., 2013). Across our dataset, 'acquisitive', i.e. high-SLA, plants tend to be characterized by higher efficiency in terms of the apparent (calibrated) leaf hydraulic conductivity (Fig. 5F). Finally, based on 7 of the 18 species for which data were available, we find that observed turgor loss point $\left(\tilde{\psi}_{\mathrm{tlp}}\right)$ is correlated with modelpredicted $\psi_{\mathrm{g} 88}$ and $\psi_{\mathrm{g} 50}$, and lies in-between these two points (Fig. S6). This means that turgor loss occurred slightly before stomatal closure in these species (Farrell et al., 2017). However, more data is required to confirm this finding.

Plants span a continuum of stomatal regulation strategies (Klein, 2014). At one end are isohydric species that maintain a constant leaf water potential by closing the stomata as soil water potential decreases, but at the cost of reduced carbon assimilation. At the other end are extreme anisohydric species that keep their stomata open even in the face of decreasing soil water potential to maintain high $\mathrm{CO}_{2}$ uptake, but risking hydraulic failure. In between are isohydrodynamic species, which maintain a relatively constant soil-to-leaf water potential difference. The initial slope of the $\psi_{1}$ vs $\psi_{\mathrm{s}}$ 
relationship determines the 'isohydricity' for each species ( $<1$ for isohydric and $>1$ for anisohydric species). In our model, the isohydric or anisohydric behaviour emerges naturally, depending on how traits interact with the balance of photosynthetic benefits and hydraulic costs. Broadly consistent with global patterns (Martínez-Vilalta et al., 2014), most species in our dataset seem to follow the isohydrodynamic or slightly anisohydric strategy (Fig. S8), but we lack data to test species-specific predictions.
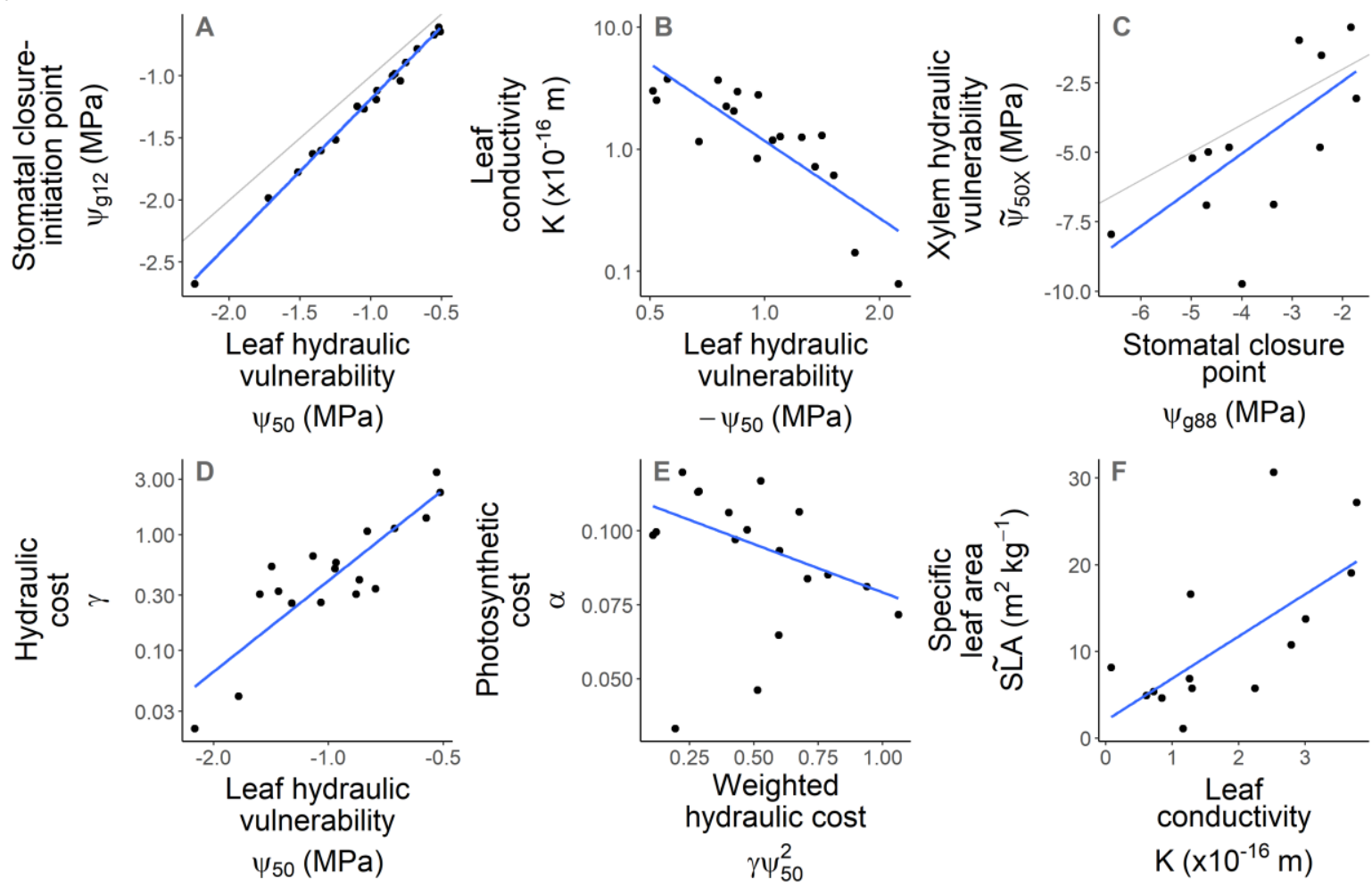

Fig. 5. Fitted parameters reveal a spectrum of hydraulic and economic strategies and recover several widely observed empirical patterns. (A) Stomatal closure begins slightly before $50 \%$ leaf conductivity is lost, i.e., loss of leaf conductivity is the trigger for stomatal closure. (B) Leaf conductivity is negatively correlated with leaf $\psi_{50}$, implying a clear safety-efficiency tradeoff at the leaf level. (C) Xylem vulnerability is almost always less than $50 \%$ at $88 \%$ stomatal closure, which means that plants close their stomata before the onset of xylem embolism. (D) Hydraulic costs are strongly correlated with $\psi_{50}$, implying that plants with higher $\psi_{50}$ have lower risks of hydraulic failure. (E) Perceived hydraulic costs (normalized) are weakly negatively correlated with perceived photosynthetic costs, implying a tradeoff in photosynthetic vs hydraulic capacities. (F) Leaves with higher specific leaf area (SLA) also have higher leaf conductivity (K), i.e., leaf economics are coordinated with leaf hydraulics. (Notations: $\psi_{g 12}$ and $\psi_{g 88}$ - leaf water potential at $12 \%$ and $88 \%$ stomatal closure respectively (MPa); $\psi_{50}$ - water potential at $50 \%$ loss of leaf conductivity (MPa). Sources for observed data $\left(\widetilde{\psi}_{50 X}\right.$ and $\left.\widetilde{S L A}\right)$ are given in Table 1.

\section{Discussion}

We have presented an analytical trait-based optimality model, unifying plant photosynthesis and hydraulics to predict the stomatal responses and biochemical acclimation of plants to changing hydroclimates. The model successfully explained the widely observed phenomena that we set out to capture. These are: (i) Assimilation and transpiration rates declined under soil drought even as light intensity remained constant (Fig. 1A,B); (ii) Photosynthetic capacity declined with progressive soil drought (Fig. 1E,F); (iii) Our model reproduced realistic relationships between logit $(\chi)$ and $\log (D)$; (iv) Stomatal closure was initiated by the loss of leaf hydraulic conductivity (Fig. $5 \mathrm{~A}$ ), and ended before 
the onset of xylem embolism (Fig. 5B); (v) values of safety margins were low on average among the investigated plant species (Fig. 5B); and (vi) isohydric or anisohydric behaviour emerged from the balance of photosynthetic benefits and hydraulic costs, without the need of a parameter to exclusively specify this behaviour. (Fig. S8).

Our model is validated in three ways. First, we have compared the predicted stomatal and photosynthetic responses to soil drought using experimental data on 18 species (Zhou et al., 2013). Second, we have validated the dependency of $\chi$ on VPD by comparison with reported data from a cross-species synthesis (Dong et al., 2020), and the dependencies of photosynthesis on temperature, VPD, and $\mathrm{CO}_{2}$ by comparison to Wang et al (2017), which in turn has strong empirical support (Lavergne et al., 2020). Third, we have compared the broad patterns emerging from fitted trait values to several empirically well-supported hypotheses (Choat et al., 2012; Scoffoni et al., 2017; Choat et al., 2018).

\subsection{Coordination of hydraulic traits and drought survival strategies}

As plants face increasing water stress, their first line of defence against irreversible hydraulic damage is to close the stomata and prevent water potentials from reaching damaging levels in the stem. If water stress continues to increase beyond the point of stomatal closure, plants begin to shed their leaves to prevent loss of water through cuticular tissue (Choat et al., 2018). Partial shedding of leaves could also be a strategy to reduce transpiration demand, allowing stomata to remain open. This mechanism of photosynthetic recovery by leaf shedding should be particularly important for tall trees and for species with lower stem conductivity, in which the stem also becomes the limiting hydraulic pathway. Recent long-term drought experiments hint at this (Zhou et al., 2016), but more data is needed to adequately model leaf-shedding responses.

Our model can be readily extended to provide predictions of carbon assimilation and its response to drying soils over multiple timescales. At the shortest timescale (minutes-days), plants may optimize leaf water potential for a fixed (acclimated) photosynthetic capacity. On the timescale of weeks, which forms the focus of this work, plants may adjust their photosynthetic capacities. This timescale can either be modelled with nested optimization (i.e., optimizing daily, or sub-daily, stomatal conductance for a given photosynthetic capacity, and optimizing weekly photosynthetic capacity by maximizing the total profit over a week), or with simultaneous optimization (i.e., optimizing both variables together by assuming a constant environment during the week, representative for mean daytime conditions). In this work, we have taken the latter approach for theoretical and computational simplicity. Optimality at even longer timescales is also conceivable. On monthly timescales, plants may be able to reduce transpiration demand by shedding leaves; and on annualto-decadal timescales, plants may adapt the characteristics and architecture of the transpiration pathway, which would be reflected in altered hydraulic traits (Rungwattana et al., 2018). Here, we have distilled trait-adaptation into a simple hypothesis that constrains the trait values. However, trait adaptation could be explicitly modelled by embedding our leaf-level optimality theory into models that predict traits using optimality (Deans et al., 2020) or evolutionary stable strategies (Dybzinski et al., 2011; Hikosaka and Anten, 2012; Franklin et al., 2020) at the whole-plant level..

Our model uses five parameters (three hydraulic traits and two cost parameters). However, principal components analysis reveals that only three principal components explain $85 \%$ variance in the trait values (Fig. S10). Moreover, $\alpha, \gamma$, and $b$ are already nearly orthogonal, which means other traits could be expressed as functions of them. Furthermore, $\alpha$ itself can be expressed as a linear combination of $\gamma \psi_{50}^{2}$ and $b(\mathrm{p}=0.016)$, suggesting that a latent parameter could be replaced with a measurable trait. If these relationships are widely attested, the number the number of parameters in 
our model may be further reduced. Alternatively, our model can also be reversed to infer traits and cost-parameters from gas-exchange measurements.

\subsection{Comparison with other stomatal optimization models}

Leaf photosynthesis is known to be jointly constrained by stomatal and non-stomatal limitations. Stomatal limitation is the constraint imposed by the stomatal opening on the diffusion of $\mathrm{CO}_{2}$. Nonstomatal limitations include the constraints imposed by leaf mesophyll, photosynthetic capacity, and sugar transport. A vast majority of photosynthesis models account only for stomatal limitations, where stomatal conductance (or equivalently, $\chi$ or $\Delta \psi$ ) is optimized to maximize photosynthetic gain. Recent models which do account for non-stomatal limitations do so using a pre-determined functional response, where mesophyll conductance (Dewar et al., 2018) or photosynthetic capacity (Hölttä et al., 2017; Sperry et al., 2017; Dewar et al., 2018) is scaled in a prescribed way with stomatal conductance. The assumption here is that stomatal and non-stomatal limitations are coordinated. To our knowledge, the multivariate optimization model presented here is the first to optimize photosynthetic capacity concurrently with stomatal conductance. Indeed, through optimality considerations, our model predicts the observed S-shaped decline of $V_{\text {cmax }}$ in response to drying soil (Kanechi et al., 1996) from first principles, rather than relying on an a priori, empirically determined functional response. This is relevant when applying the model to conditions outside the domain of environmental factors used for calibration (e.g., elevated $\mathrm{CO}_{2}$ ), where such empirical relationships cannot be assumed to remain identical.

Almost all models of stomatal optimization focus on water transport through the xylem. However, our data and results support the growing body of evidence that the leaf is the hydraulic bottleneck of the plant (Sack and Holbrook, 2006; Scoffoni et al., 2017). Thus, we find that for most species, the

fitted values of $\psi_{50}$ are less negative than the corresponding observed values for xylem $\left(\tilde{\psi}_{50 \mathrm{x}}\right)$. Since xylem embolism is strongly linked to plant mortality under drought (Skelton et al., 2018), plant traits should adapt such that on one hand, the plant should be able to fully utilize the hydraulically feasible range of leaf water potentials under non-stressed conditions, and on the other hand, respond fast enough by closing the stomata before the onset of xylem embolism. In our model, the former is encoded in the leaf-hydraulic efficiency hypothesis, whereas the latter emerges from optimality considerations.

\subsection{Model assumptions and limitations}

Under extreme hydroclimatic conditions, such as extremely dry or flooded soils, or extremely low atmospheric $\mathrm{CO}_{2}$ levels, our model predictions deviate slightly from the observed data. In most of the species in our dataset, we observe an increase in $\chi$ after stomatal closure. However, our model suggests that as photosynthesis becomes electron-transport limited due to decline in $J_{\max }, \chi$ becomes independent of soil moisture, and asymptotically approaches a constant value (Eq. S14). The build-up of $\mathrm{CO}_{2}$ in the leaf could happen via two mechanisms: (i) if dark respiration does not decline in proportion to assimilation, or (ii) if both assimilation and respiration decline due to declining photosynthetic activity, but $\mathrm{CO}_{2}$ continues to 'leak in' through the leaf cuticle (Boyer et al., 1997). Since the source of $\mathrm{CO} 2$ is different in the two mechanisms (plant or air), these mechanisms could be distinguished based on whether the build-up is also detected in $\delta^{13} C$ measurements. Mathematically, the two mechanisms could be accounted for by using a non-linear dependence of dark respiration on $V_{\mathrm{cmax}}$, and by explicitly accounting for cuticular conductance, respectively. Practically, however, these inconsistencies in the predictions of $\chi$ only arise well after stomata are closed, and therefore do not impact other predictions. 
A key process that we have not accounted for in our model is the leaf energy balance. Under drying soil, reduced transpiration should raise the leaf temperature, which in turn would affect the photosynthetic capacities and the dark-respiration rate. Inclusion of the leaf energy balance in our model could therefore be a promising direction for further research.

For deriving the analytical solution of our model, we have assumed that the leaf is the hydraulic bottleneck of the plant. This assumption was especially suitable for our dataset because all measurements were made on saplings of $<1 \mathrm{~m}$ height, for whom the potential drop along the stem would be negligible. However, this makes stomatal responses independent of tree height. The stem hydraulic conductivity (per unit leaf area) is given by $K_{\mathrm{S}} v_{\mathrm{H}} / H$, where $K_{S}$ is the sapwood permeability that depends on the xylem vessel geometry, $v_{\mathrm{H}}$ is the ratio of sapwood area to leaf area, and $H$ is height. One possibility is that plants maintain stem conductivity as they grow taller by reducing leaf area or by tapering xylem vessels, as has been postulated by the metabolic theory (West et al., 1999) and widely observed in nature (Anfodillo et al., 2006; Olson et al., 2014). Another possibility is that as plants grow taller, the stem does become hydraulically limiting (Niklas and Spatz, 2004; Givnish et al., 2014), as other studies suggest. Explicit stem hydraulics (i.e., segmented hydraulic pathways) can be readily integrated in the numerical version of our model, which could thus become a robust tool to investigate these alternative hypotheses.

\subsection{Implications for vegetation modelling}

Photosynthesis and transpiration by terrestrial plants account for $56 \%$ and $30 \%$ of the global fluxes of carbon dioxide and water respectively (Jasechko et al., 2013; Le Quéré et al., 2018). Therefore, accurate models of plant photosynthesis are crucial for improving the projections of the global carbon and water cycles, especially in response to unprecedented future climatic conditions projecting an increase in the frequency of droughts globally. Inclusion of plant hydraulics into vegetation models has been shown to improve predictions of global GPP and evapotranspiration (Hickler et al., 2006; Bonan et al., 2014; Christoffersen et al., 2016; Kennedy et al., 2019; Eller et al., 2020) and the spatiotemporal diversity of vegetation (Xu et al., 2016). In our model, explicit inclusion of plant hydraulics allows separating the stomatal responses to atmospheric drought and soil moisture availability. This separation could be particularly useful for remote-sensing based models of GPP. Accounting for biochemical acclimation allows us to predict GPP without an a priori knowledge of photosynthetic capacity. This allows the model to not only capture plant species for which trait data is currently limited, but also to predict responses of hypothetical species which currently do not exist, but could evolve under future climates. Furthermore, accounting for photosynthetic and hydraulic costs should yield more accurate estimates of the energy spent for resource acquisition, and consequently better estimates of the resources available for growth and reproduction. Therefore, embedding our model of photosynthesis into a demographic model should improve the scaling of photosynthesis and transpiration from leaf level to whole plant level, and even from plants to communities, thus paving the way for robust improvements to existing land surface models. 


\section{Methods}

\subsection{Water-balance principle}

The water balance principle states that the atmospheric demand for water imposed by vapour pressure deficit at the leaf surface, must be met by the supply of water from the soil via the stem and leaf segments of the hydraulic pathway. As tissues desiccate and vessels become embolized under high suction on the water column, the conductivity $K_{\mathrm{L}}$ of any cross-section of the pathway declines as the water potential becomes increasingly negative. This decline in conductivity is described by a vulnerability curve $P(\psi)$, such that $K_{\mathrm{L}}(\psi)=K_{\mathrm{L}}(0) P(\psi)$. The vulnerability curve is typically described by two parameters - the water potential at which $50 \%$ conductivity is lost $\left(\psi_{50}\right)$ and a shape parameter $b$ that determines the rate of conductivity loss. It is conveniently described by a Weibull function,

$$
P(\psi)=(1 / 2)^{\left(\psi / \psi_{50}\right)^{b}} .
$$

The path of water inside the plant consists of several segments (Fig. 1). First, water flows through the stem xylem vessels up to the petiole. From there, it continues flowing through the xylem in the leaf veins. Finally, after exiting the vein, it flows through the bundle sheath and spongy mesophyll cells up to the stomata, from where it evaporates from the cell walls and diffuses through the stomata into the atmosphere. Water potential drops continuously along the pathway, from $\psi_{\mathrm{s}}$ in the soil to $\psi_{\mathrm{p}}$ at the end of the vein, and $\psi_{l}$ at the leaf surface. Given the conductivities and the vulnerability curves for the xylem and outside-xylem segments of the pathway, we can readily express the potential difference along the xylem segment (from the soil to the end of the vein, $\Delta \psi_{\mathrm{x}}$ ), and the potential difference along the outside-xylem segment (between the end of the vein and the leaf surface, $\Delta \psi_{\text {ox }}$ ) in terms of transpiration rate as follows (please refer to SI Section 1.1.3 for derivation),

$$
E=-\frac{K_{\mathrm{s}} v_{\mathrm{H}}}{H \eta} \int_{\psi_{\mathrm{s}}}^{\psi_{\mathrm{p}}} P_{\mathrm{x}}(\psi) d \psi=-\frac{K_{\mathrm{l}}}{\Delta L \eta} \int_{\psi_{\mathrm{p}}}^{\psi_{\mathrm{l}}} P_{\mathrm{ox}}(\psi) d \psi=1.6 g_{\mathrm{s}} D,
$$

in which $E$ is transpiration rate per unit leaf area, $K_{\mathrm{S}}$ is the sapwood permeability, $v_{\mathrm{H}}$ is the sapwood area to leaf area ratio, $H$ is plant height, $K_{1}$ is leaf (outside-xylem) conductivity per unit leaf area, $\Delta L$ is the length of the outside-xylem pathway, and $\eta$ is the viscosity of water, $g_{\mathrm{s}}$ is the stomatal conductance, and $D$ is the vapour pressure deficit normalized by the atmospheric pressure. The path length $\Delta L$ may depend on the leaf thickness (or equivalently, leaf mass per unit area, $L M A$ ) and the vein length per unit leaf area (VLA) (Nardini et al., 2012). Since the total soil-to-leaf potential difference is $\Delta \psi=\Delta \psi_{\mathrm{x}}+\Delta \psi_{\mathrm{ox}}$, Eq. 3 can be solved for $\psi_{\mathrm{p}}$ and $g_{\mathrm{s}}$ for any given $\Delta \psi$.

There is increasing evidence that the leaf is the hydraulic bottleneck in the flow of water through the plant. This manifests in two ways: 1 ) The xylem conductivity is much larger than the leaf conductivity. Thus, the drop in water potential along the xylem pathway is much lesser compared to that in the outside-xylem pathway $\left(\Delta \psi_{\mathrm{x}} \ll \Delta \psi_{\mathrm{ox}}\right)$, and 2$)$ the operating water potential (water potential until stomatal closure) in the xylem is not large enough to cause embolism $\left(P_{\mathrm{x}}(\psi) \approx 1\right.$ in the xylem). With these assumptions, $\Delta \psi \approx \Delta \psi_{\mathrm{ox}}$. This allows us to simplify the water balance hypothesis (enabling an analytical solution) and reduces the number of hydraulic traits required to drive the model, as we no longer require xylem traits: 


$$
E=-\frac{K_{\mathrm{l}}}{\Delta L \eta} \int_{\psi_{\mathrm{s}}}^{\psi_{\mathrm{s}}-\Delta \psi} P_{\mathrm{ox}}(\psi) d \psi=1.6 g_{s} D .
$$

To further simplify the notations, we refer to the net conductivity (after accounting for path length) as $K$, i.e. $K=K_{\mathrm{l}} / \Delta L$, and to the outside-xylem vulnerability curve as $P()$ (without the subscript).

\subsection{Photosynthetic coordination hypothesis}

The coordination hypothesis states that under typical daytime conditions, assimilation operates at the point of co-limitation, such that the carboxylation-limited and electron-transport-limited assimilation rates are equal. With this assumption, the co-limited assimilation rate can be written as

$$
A=\phi_{0} I_{\mathrm{abs}} m_{\mathrm{j}} \frac{\chi c_{\mathrm{a}}\left(1-b_{r}\right)-\left(\Gamma^{*}+b_{\mathrm{r}} K_{\mathrm{M}}\right)}{\chi c_{\mathrm{a}}+2 \Gamma^{*}},
$$

in which $m_{j}$ describes the saturation in light-use efficiency due to limitation by $J_{\max }$,

$$
m_{\mathrm{j}}=\frac{1}{\sqrt{1+\left(\frac{4 \phi_{0} I_{\mathrm{abs}}}{J_{\max }}\right)^{2}}}
$$

Here $c_{\mathrm{a}}$ is the atmospheric $\mathrm{CO}_{2}$ concentration, $\chi$ is the ratio of the leaf-internal and external $\mathrm{CO}_{2}$ concentrations $\left(c_{\mathrm{i}}: c_{\mathrm{a}}\right), \Gamma^{*}$ is the light compensation point, $K_{\mathrm{M}}$ is the Michaelis-Menten coefficient for C3 photosynthesis, $\phi_{0}$ is the quantum yield efficiency, $I_{\mathrm{abs}}$ is the absorbed photosynthetically active radiation, and $b_{\mathrm{r}}$ is the ratio of dark respiration to carboxylation capacity (dark respiration is assumed to be proportional to carboxylation capacity, i.e. $\left.R_{\mathrm{d}}=b_{\mathrm{r}} V_{\text {cmax }}\right)$. Temperature dependencies of $\Gamma^{*}$ and $K_{\mathrm{M}}$ are modelled according to Stocker et al., (2020). The ratio $b_{\mathrm{r}}$ also has a weak dependence on temperature ( $\mathrm{H}$. Wang et al., 2020), which we have ignored in this work. Variation in $J_{\max }$ in response to light and water availability (by optimization) implies a coordinated variation in both carboxylation and electron transport capacities.

\subsection{Profit-maximization hypothesis}

We assume that plants maximize net assimilation (or profit, $F$ ) defined as

$$
F=A-\alpha J_{\max }-\gamma \Delta \psi^{2} .
$$

Without loss of generality, we have assumed that the unit benefit of assimilation is one, i.e. $\alpha$ and $\gamma$ represent the ratios of the unit costs to unit benefits of assimilation.

To optimize Eq. 7, we express all quantities in terms of the two independent variables $\chi$ and $\Delta \psi$ and set the gradient of the profit function to 0 . This can be done analytically (Eq. S13). However, except in the special case of strong $J_{\max }$ limitation, the roots of the gradient must be found numerically. Solving for optimal $\chi^{*}$ and $\Delta \psi^{*}$ in turn allows us to predict the optimal photosynthetic capacities $\left(V_{\text {cmax }}^{*}\right.$ and $\left.J_{\max }^{*}\right)$, stomatal conductance $\left(g_{\mathrm{s}}^{*}\right)$, and $\mathrm{CO}_{2}$ assimilation rate $\left(A^{*}\right)$.

\subsection{Leaf-hydraulic efficiency hypothesis}

This hypothesis states that plants fully utilize available leaf hydraulic capacity under normal operating conditions. Since $\psi_{50}$ is an indicator of damaging water potentials for the leaf, we assume that the soil-leaf water potential difference under wet (not water-stressed) conditions is equal to leaf $\psi_{50}$ (i.e. of the outside xylem hydraulic pathway). Note that this equality is not imposed directly 
on the values of leaf water potential, but is instead used to constrain the model parameters by adding to the error term (see below).

\subsection{Model validation and testing}

\subsubsection{Environmental drivers and other model parameters}

We drive the model with environmental variables (temperature, vapour pressure deficit, light intensity, and $\mathrm{CO}_{2}$ ) as specified in the experimental studies. For four of the 18 species (Allocasuarina Luehmannii, Eucalyptus pilularis, Eucalyptus populnea, and Gycine max), light intensity was reported only qualitatively, or only the minimum value was reported. For such species, we iteratively estimated it from the joint response of $A$ and $\chi$. Other parameters used in the model are as follows: $\phi_{0}=0.087, b_{\mathrm{r}}=0.02$.

\subsubsection{Error evaluation}

The error between predictions and observations for each species is defined as

$$
E_{r}=\sum_{i}\left(\frac{A_{i}-\tilde{A}_{i}}{E\left[\tilde{A}_{i}\right]}\right)^{2}+\sum_{i}\left(\frac{g_{s, i}-\tilde{g}_{s, i}}{E\left[\tilde{g}_{s, i}\right]}\right)^{2}+\sum_{i}\left(\frac{\chi_{i}-\tilde{\chi}_{i}}{E\left[\tilde{\chi}_{i}\right]}\right)^{2}+\sum_{i} w_{i}\left(\frac{\Delta \psi_{i}-\psi_{50}}{E\left[\Delta \psi_{i}\right]}\right)^{2},
$$

in which $i$ represents different values of $\psi_{s}, E[]$ denotes the mean value, and variables with tilde (e.g., $\tilde{\chi}$ ) represent observations. The last term comes from the leaf-hydraulic efficiency hypothesis, where we constrain $\Delta \psi$ to equal $\psi_{50}$. Since $\Delta \psi$ is constrained only under well-watered conditions, we use a weight function in the last term, $w\left(\psi_{s}\right)=1$ for $\left|\psi_{s}\right|<\left|\psi_{50}\right|$, and 0 otherwise.

\subsubsection{Cross validation}

To evaluate the generalizability of the model, we performed 5 -fold cross validation for each species.

\subsection{P-hydro R package}

$\mathrm{R}$ code to run our model ("P-hydro") is provided as an extension of the rpmodel package ( https://github.com/jaideep777/rpmodel/tree/hydraulics), with options to use the semi-analytical solution derived in this work, or to directly optimize the profit function numerically. The numerical method also allows for quick extension of the model with different profit and cost functions.

\section{Acknowledgements}

We thank Oskar Franklin for discussions and feedback on the manuscript. JJ and UD acknowledge funding from the European Commission through a Marie Skłodowska-Curie Actions fellowship (Project No. 84128 - Plant-FATE). JJ, FH, and UD gratefully acknowledge funding from the International Institute for Applied Systems Analysis (IIASA) and the National Member Organizations that support the institute. JJ also gratefully acknowledges support from the Divecha Centre for Climate Change, Indian Institute of Science in the form of initial funding. This work is a contribution to the Imperial College initiative on Grand Challenges in Ecosystems and the Environment and has received funding from the European Research Council (ERC) under the European Union's Horizon 2020 research and innovation programme (grant agreement No: 787203 REALM). 


\section{References}

Anderegg, W.R.L., Wolf, A., Arango-Velez, A., Choat, B., Chmura, D.J., Jansen, S., Kolb, T., Li, S., Meinzer, F.C., Pita, P., Resco de Dios, V., Sperry, J.S., Wolfe, B.T., Pacala, S., 2018. Woody plants optimise stomatal behaviour relative to hydraulic risk. Ecol. Lett. 21, 968-977. https://doi.org/10.1111/ele.12962

Anfodillo, T., Carraro, V., Carrer, M., Fior, C., Rossi, S., 2006. Convergent tapering of xylem conduits in different woody species. New Phytol. 169, 279-290. https://doi.org/10.1111/j.14698137.2005.01587.x

Bartlett, M.K., Detto, M., Pacala, S.W., 2019. Predicting shifts in the functional composition of tropical forests under increased drought and $\mathrm{CO} 2$ from trade-offs among plant hydraulic traits. Ecol. Lett. 22, 67-77. https://doi.org/10.1111/ele.13168

Bonan, G.B., Williams, M., Fisher, R.A., Oleson, K.W., 2014. Modeling stomatal conductance in the earth system: linking leaf water-use efficiency and water transport along the soil-plantatmosphere continuum. Geosci Model Dev 7, 2193-2222. https://doi.org/10.5194/gmd-72193-2014

Boyer, J.S., Wong, S.C., Farquhar, G.D., 1997. CO2 and Water Vapor Exchange across Leaf Cuticle (Epidermis) at Various Water Potentials. Plant Physiol. 114, 185-191. https://doi.org/10.1104/pp.114.1.185

Brodribb, T.J., Bowman, D.J.M.S., Nichols, S., Delzon, S., Burlett, R., 2010. Xylem function and growth rate interact to determine recovery rates after exposure to extreme water deficit. New Phytol. 188, 533-542. https://doi.org/10.1111/j.1469-8137.2010.03393.x

Brodribb, T.J., Cochard, H., 2009. Hydraulic Failure Defines the Recovery and Point of Death in Water-Stressed Conifers. Plant Physiol. 149, 575-584. https://doi.org/10.1104/pp.108.129783

Brodribb, T.J., Holbrook, N.M., Edwards, E.J., Gutiérrez, M.V., 2003. Relations between stomatal closure, leaf turgor and xylem vulnerability in eight tropical dry forest trees. Plant Cell Environ. 26, 443-450. https://doi.org/10.1046/j.1365-3040.2003.00975.x

Buckley, T.N., John, G.P., Scoffoni, C., Sack, L., 2015. How Does Leaf Anatomy Influence Water Transport outside the Xylem? Plant Physiol. 168, 1616-1635. https://doi.org/10.1104/pp.15.00731

Chen, J.-L., Reynolds, J.F., Harley, P.C., Tenhunen, J.D., 1993. Coordination theory of leaf nitrogen distribution in a canopy. Oecologia 93, 63-69. https://doi.org/10.1007/BF00321192

Choat, B., Ball, M.C., Luly, J.G., Holtum, J.A.M., 2005. Hydraulic architecture of deciduous and evergreen dry rainforest tree species from north-eastern Australia. Trees 19, 305-311. https://doi.org/10.1007/s00468-004-0392-1

Choat, B., Brodribb, T.J., Brodersen, C.R., Duursma, R.A., López, R., Medlyn, B.E., 2018. Triggers of tree mortality under drought. Nature 558, 531-539. https://doi.org/10.1038/s41586-0180240-x

Choat, B., Jansen, S., Brodribb, T.J., Cochard, H., Delzon, S., Bhaskar, R., Bucci, S.J., Feild, T.S., Gleason, S.M., Hacke, U.G., Jacobsen, A.L., Lens, F., Maherali, H., Martínez-Vilalta, J., Mayr, S., Mencuccini, M., Mitchell, P.J., Nardini, A., Pittermann, J., Pratt, R.B., Sperry, J.S., Westoby, M., Wright, I.J., Zanne, A.E., 2012. Global convergence in the vulnerability of forests to drought. Nature 491, 752-755. https://doi.org/10.1038/nature11688

Christoffersen, B.O., Gloor, M., Fauset, S., Fyllas, N.M., Galbraith, D.R., Baker, T.R., Kruijt, B., Rowland, L., Fisher, R.A., Binks, O.J., Sevanto, S., Xu, C., Jansen, S., Choat, B., Mencuccini, M., McDowell, N.G., Meir, P., 2016. Linking hydraulic traits to tropical forest function in a sizestructured and trait-driven model (TFS v.1-Hydro). Geosci. Model Dev. 9, 4227-4255. https://doi.org/10.5194/gmd-9-4227-2016

Cowan, I.R., Farquhar, G.D., 1977. Stomatal function in relation to leaf metabolism and environment. Symp. Soc. Exp. Biol. 31, 471-505. 
Damour, G., Simonneau, T., Cochard, H., Urban, L., 2010. An overview of models of stomatal conductance at the leaf level. Plant Cell Environ. 33, 1419-1438.

https://doi.org/10.1111/j.1365-3040.2010.02181.x

Deans, R.M., Brodribb, T.J., Busch, F.A., Farquhar, G.D., 2020. Optimization can provide the fundamental link between leaf photosynthesis, gas exchange and water relations. Nat. Plants 6, 1116-1125. https://doi.org/10.1038/s41477-020-00760-6

Dewar, R., Mauranen, A., Mäkelä, A., Hölttä, T., Medlyn, B., Vesala, T., 2018. New insights into the covariation of stomatal, mesophyll and hydraulic conductances from optimization models incorporating nonstomatal limitations to photosynthesis. New Phytol. 217, 571-585. https://doi.org/10.1111/nph.14848

Dong, N., Prentice, I.C., Wright, I.J., Evans, B.J., Togashi, H.F., Caddy-Retalic, S., McInerney, F.A., Sparrow, B., Leitch, E., Lowe, A.J., 2020. Components of leaf-trait variation along environmental gradients. New Phytol. n/a. https://doi.org/10.1111/nph.16558

Dybzinski, R., Farrior, C., Wolf, A., Reich, P.B., Pacala, S.W., 2011. Evolutionarily Stable Strategy Carbon Allocation to Foliage, Wood, and Fine Roots in Trees Competing for Light and Nitrogen: An Analytically Tractable, Individual-Based Model and Quantitative Comparisons to Data. Am. Nat. 177, 153-166. https://doi.org/10.1086/657992

Eller, C.B., Rowland, L., Mencuccini, M., Rosas, T., Williams, K., Harper, A., Medlyn, B.E., Wagner, Y., Klein, T., Teodoro, G.S., Oliveira, R.S., Matos, I.S., Rosado, B.H.P., Fuchs, K., Wohlfahrt, G., Montagnani, L., Meir, P., Sitch, S., Cox, P.M., 2020. Stomatal optimization based on xylem hydraulics (SOX) improves land surface model simulation of vegetation responses to climate. New Phytol. 226, 1622-1637. https://doi.org/10.1111/nph.16419

Ennajeh, M., Tounekti, T., Vadel, A.M., Khemira, H., Cochard, H., 2008. Water relations and droughtinduced embolism in olive (Olea europaea) varieties 'Meski' and 'Chemlali' during severe drought. Tree Physiol. 28, 971-976. https://doi.org/10.1093/treephys/28.6.971

Farquhar, G.D., Caemmerer, S. von, Berry, J.A., 1980. A biochemical model of photosynthetic CO $<$ Subscript $>2</$ Subscript $>$ assimilation in leaves of $C<$ Subscript $>3</$ Subscript $>$ species. Planta 149, 78-90. https://doi.org/10.1007/BF00386231

Farrell, C., Szota, C., Arndt, S.K., 2017. Does the turgor loss point characterize drought response in dryland plants? Plant Cell Environ. 40, 1500-1511. https://doi.org/10.1111/pce.12948

Flexas, J., Scoffoni, C., Gago, J., Sack, L., 2013. Leaf mesophyll conductance and leaf hydraulic conductance: an introduction to their measurement and coordination. J. Exp. Bot. 64, 39653981. https://doi.org/10.1093/jxb/ert319

Franklin, O., Harrison, S.P., Dewar, R., Farrior, C.E., Brännström, Å., Dieckmann, U., Pietsch, S., Falster, D., Cramer, W., Loreau, M., Wang, H., Mäkelä, A., Rebel, K.T., Meron, E., Schymanski, S.J., Rovenskaya, E., Stocker, B.D., Zaehle, S., Manzoni, S., van Oijen, M., Wright, I.J., Ciais, P., van Bodegom, P.M., Peñuelas, J., Hofhansl, F., Terrer, C., Soudzilovskaia, N.A., Midgley, G., Prentice, I.C., 2020. Organizing principles for vegetation dynamics. Nat. Plants 6, 444-453. https://doi.org/10.1038/s41477-020-0655-x

Givnish, T.J., Wong, S.C., Stuart-Williams, H., Holloway-Phillips, M., Farquhar, G.D., 2014. Determinants of maximum tree height in Eucalyptus species along a rainfall gradient in Victoria, Australia. Ecology 95, 2991-3007. https://doi.org/10.1890/14-0240.1

Gleason, S.M., Westoby, M., Jansen, S., Choat, B., Hacke, U.G., Pratt, R.B., Bhaskar, R., Brodribb, T.J., Bucci, S.J., Cao, K.-F., Cochard, H., Delzon, S., Domec, J.-C., Fan, Z.-X., Feild, T.S., Jacobsen, A.L., Johnson, D.M., Lens, F., Maherali, H., Martínez-Vilalta, J., Mayr, S., McCulloh, K.A., Mencuccini, M., Mitchell, P.J., Morris, H., Nardini, A., Pittermann, J., Plavcová, L., Schreiber, S.G., Sperry, J.S., Wright, I.J., Zanne, A.E., 2016. Weak tradeoff between xylem safety and xylem-specific hydraulic efficiency across the world's woody plant species. New Phytol. 209, 123-136. https://doi.org/10.1111/nph.13646 
Grieu, P., Guehl, J.M., Aussenac, G., 1988. The effects of soil and atmospheric drought on photosynthesis and stomatal control of gas exchange in three coniferous species. Physiol. Plant. 73, 97-104. https://doi.org/10.1111/j.1399-3054.1988.tb09199.x

Guerrieri, R., Belmecheri, S., Ollinger, S.V., Asbjornsen, H., Jennings, K., Xiao, J., Stocker, B.D., Martin, M., Hollinger, D.Y., Bracho-Garrillo, R., Clark, K., Dore, S., Kolb, T., Munger, J.W., Novick, K., Richardson, A.D., 2019. Disentangling the role of photosynthesis and stomatal conductance on rising forest water-use efficiency. Proc. Natl. Acad. Sci. 116, 16909-16914. https://doi.org/10.1073/pnas.1905912116

Hickler, T., Prentice, I.C., Smith, B., Sykes, M.T., Zaehle, S., 2006. Implementing plant hydraulic architecture within the LPJ Dynamic Global Vegetation Model. Glob. Ecol. Biogeogr. 15, 567577. https://doi.org/10.1111/j.1466-8238.2006.00254.x

Hikosaka, K., Anten, N.P.R., 2012. An evolutionary game of leaf dynamics and its consequences for canopy structure. Funct. Ecol. 26, 1024-1032. https://doi.org/10.1111/j.13652435.2012.02042.x

Hölttä, T., Lintunen, A., Chan, T., Mäkelä, A., Nikinmaa, E., 2017. A steady-state stomatal model of balanced leaf gas exchange, hydraulics and maximal source-sink flux. Tree Physiol. 37, 851868. https://doi.org/10.1093/treephys/tpx011

Jasechko, S., Sharp, Z.D., Gibson, J.J., Birks, S.J., Yi, Y., Fawcett, P.J., 2013. Terrestrial water fluxes dominated by transpiration. Nature 496, 347-350. https://doi.org/10.1038/nature11983

Kanechi, M., Uchida, N., Yasuda, T., Yamaguchi, T., 1996. Non-Stomatal Inhibition Associated with Inactivation of Rubisco in Dehydrated Coffee Leaves under Unshaded and Shaded Conditions. Plant Cell Physiol. 37, 455-460. https://doi.org/10.1093/oxfordjournals.pcp.a028967

Kattge, J., Díaz, S., Lavorel, S., Prentice, I.C., Leadley, P., Bönisch, G., Garnier, E., Westoby, M., Reich, P.B., Wright, I.J., Cornelissen, J.H.C., Violle, C., Harrison, S.P., Bodegom, P.M.V., Reichstein, M., Enquist, B.J., Soudzilovskaia, N.A., Ackerly, D.D., Anand, M., Atkin, O., Bahn, M., Baker, T.R., Baldocchi, D., Bekker, R., Blanco, C.C., Blonder, B., Bond, W.J., Bradstock, R., Bunker, D.E., Casanoves, F., Cavender-Bares, J., Chambers, J.Q., lii, F.S.C., Chave, J., Coomes, D., Cornwell, W.K., Craine, J.M., Dobrin, B.H., Duarte, L., Durka, W., Elser, J., Esser, G., Estiarte, M., Fagan, W.F., Fang, J., Fernández-Méndez, F., Fidelis, A., Finegan, B., Flores, O., Ford, H., Frank, D., Freschet, G.T., Fyllas, N.M., Gallagher, R.V., Green, W.A., Gutierrez, A.G., Hickler, T., Higgins, S.I., Hodgson, J.G., Jalili, A., Jansen, S., Joly, C.A., Kerkhoff, A.J., Kirkup, D., Kitajima, K., Kleyer, M., Klotz, S., Knops, J.M.H., Kramer, K., Kühn, I., Kurokawa, H., Laughlin, D., Lee, T.D., Leishman, M., Lens, F., Lenz, T., Lewis, S.L., Lloyd, J., Llusià, J., Louault, F., Ma, S., Mahecha, M.D., Manning, P., Massad, T., Medlyn, B.E., Messier, J., Moles, A.T., Müller, S.C., Nadrowski, K., Naeem, S., Niinemets, Ü., Nöllert, S., Nüske, A., Ogaya, R., Oleksyn, J., Onipchenko, V.G., Onoda, Y., Ordoñez, J., Overbeck, G., Ozinga, W.A., Patiño, S., Paula, S., Pausas, J.G., Peñuelas, J., Phillips, O.L., Pillar, V., Poorter, H., Poorter, L., Poschlod, P., Prinzing, A., Proulx, R., Rammig, A., Reinsch, S., Reu, B., Sack, L., Salgado-Negret, B., Sardans, J., Shiodera, S., Shipley, B., Siefert, A., Sosinski, E., Soussana, J.-F., Swaine, E., Swenson, N., Thompson, K., Thornton, P., Waldram, M., Weiher, E., White, M., White, S., Wright, S.J., Yguel, B., Zaehle, S., Zanne, A.E., Wirth, C., 2011. TRY - a global database of plant traits. Glob. Change Biol. 17, 2905-2935. https://doi.org/10.1111/j.1365-2486.2011.02451.x

Keeling, R.F., Graven, H.D., Welp, L.R., Resplandy, L., Bi, J., Piper, S.C., Sun, Y., Bollenbacher, A., Meijer, H.A.J., 2017. Atmospheric evidence for a global secular increase in carbon isotopic discrimination of land photosynthesis. Proc. Natl. Acad. Sci. https://doi.org/10.1073/pnas.1619240114

Kelly, J.W.G., Duursma, R.A., Atwell, B.J., Tissue, D.T., Medlyn, B.E., 2016. Drought $\times$ CO2 interactions in trees: a test of the low-intercellular CO2 concentration (Ci) mechanism. New Phytol. 209, 1600-1612. https://doi.org/10.1111/nph.13715 
Kennedy, D., Swenson, S., Oleson, K.W., Lawrence, D.M., Fisher, R., Costa, A.C.L. da, Gentine, P., 2019. Implementing Plant Hydraulics in the Community Land Model, Version 5. J. Adv. Model. Earth Syst. 11, 485-513. https://doi.org/10.1029/2018MS001500

Klein, T., 2014. The variability of stomatal sensitivity to leaf water potential across tree species indicates a continuum between isohydric and anisohydric behaviours. Funct. Ecol. 28, 13131320. https://doi.org/10.1111/1365-2435.12289

Lavergne, A., Voelker, S., Csank, A., Graven, H., Boer, H.J., Daux, V., Robertson, I., Dorado-Liñán, I., Martínez-Sancho, E., Battipaglia, G., Bloomfield, K.J., Still, C.J., Meinzer, F.C., Dawson, T.E., Julio Camarero, J., Clisby, R., Fang, Y., Menzel, A., Keen, R.M., Roden, J.S., Prentice, I.C., 2020. Historical changes in the stomatal limitation of photosynthesis: empirical support for an optimality principle. New Phytol. 225, 2484-2497. https://doi.org/10.1111/nph.16314

Le Quéré, C., Andrew, R.M., Friedlingstein, P., Sitch, S., Pongratz, J., Manning, A.C., Korsbakken, J.I., Peters, G.P., Canadell, J.G., Jackson, R.B., Boden, T.A., Tans, P.P., Andrews, O.D., Arora, V.K., Bakker, D.C.E., Barbero, L., Becker, M., Betts, R.A., Bopp, L., Chevallier, F., Chini, L.P., Ciais, P., Cosca, C.E., Cross, J., Currie, K., Gasser, T., Harris, I., Hauck, J., Haverd, V., Houghton, R.A., Hunt, C.W., Hurtt, G., Ilyina, T., Jain, A.K., Kato, E., Kautz, M., Keeling, R.F., Klein Goldewijk, K., Körtzinger, A., Landschützer, P., Lefèvre, N., Lenton, A., Lienert, S., Lima, I., Lombardozzi, D., Metzl, N., Millero, F., Monteiro, P.M.S., Munro, D.R., Nabel, J.E.M.S., Nakaoka, S., Nojiri, Y., Padin, X.A., Peregon, A., Pfeil, B., Pierrot, D., Poulter, B., Rehder, G., Reimer, J., Rödenbeck, C., Schwinger, J., Séférian, R., Skjelvan, I., Stocker, B.D., Tian, H., Tilbrook, B., Tubiello, F.N., van der Laan-Luijkx, I.T., van der Werf, G.R., van Heuven, S., Viovy, N., Vuichard, N., Walker, A.P., Watson, A.J., Wiltshire, A.J., Zaehle, S., Zhu, D., 2018. Global Carbon Budget 2017. Earth Syst. Sci. Data 10, 405-448. https://doi.org/10.5194/essd-10405-2018

Liu, C.-C., Liu, Y.-G., Guo, K., Fan, D.-Y., Yu, L.-F., Yang, R., 2011. Exploitation of patchy soil water resources by the clonal vine Ficus tikoua in karst habitats of southwestern China. Acta Physiol. Plant. 33, 93-102. https://doi.org/10.1007/s11738-010-0520-z

Liu, C.-C., Liu, Y.-G., Guo, K., Zheng, Y.-R., Li, G.-Q., Yu, L.-F., Yang, R., 2010. Influence of drought intensity on the response of six woody karst species subjected to successive cycles of drought and rewatering. Physiol. Plant. 139, 39-54. https://doi.org/10.1111/j.13993054.2009.01341.x

Liu, F., Andersen, M.N., Jacobsen, S.-E., Jensen, C.R., 2005. Stomatal control and water use efficiency of soybean (Glycine max L. Merr.) during progressive soil drying. Environ. Exp. Bot. 54, 3340. https://doi.org/10.1016/j.envexpbot.2004.05.002

Maire, V., Martre, P., Kattge, J., Gastal, F., Esser, G., Fontaine, S., Soussana, J.-F., 2012. The Coordination of Leaf Photosynthesis Links C and N Fluxes in C3 Plant Species. PLOS ONE 7, e38345. https://doi.org/10.1371/journal.pone.0038345

Manzoni, S., Vico, G., Katul, G., Palmroth, S., Porporato, A., 2014. Optimal plant water-use strategies under stochastic rainfall. Water Resour. Res. 50, 5379-5394. https://doi.org/10.1002/2014WR015375

Martínez-Vilalta, J., Poyatos, R., Aguadé, D., Retana, J., Mencuccini, M., 2014. A new look at water transport regulation in plants. New Phytol. 204, 105-115. https://doi.org/10.1111/nph.12912

Martin-StPaul, N., Delzon, S., Cochard, H., 2017. Plant resistance to drought depends on timely stomatal closure. Ecol. Lett. 20, 1437-1447. https://doi.org/10.1111/ele.12851

McDowell, N.G., Allen, C.D., Anderson-Teixeira, K., Aukema, B.H., Bond-Lamberty, B., Chini, L., Clark, J.S., Dietze, M., Grossiord, C., Hanbury-Brown, A., Hurtt, G.C., Jackson, R.B., Johnson, D.J., Kueppers, L., Lichstein, J.W., Ogle, K., Poulter, B., Pugh, T.A.M., Seidl, R., Turner, M.G., Uriarte, M., Walker, A.P., Xu, C., 2020. Pervasive shifts in forest dynamics in a changing world. Science 368. https://doi.org/10.1126/science.aaz9463 
Medlyn, B.E., Duursma, R.A., Eamus, D., Ellsworth, D.S., Prentice, I.C., Barton, C.V.M., Crous, K.Y., Angelis, P.D., Freeman, M., Wingate, L., 2011. Reconciling the optimal and empirical approaches to modelling stomatal conductance. Glob. Change Biol. 17, 2134-2144. https://doi.org/10.1111/j.1365-2486.2010.02375.x

Meinzer, F.C., Johnson, D.M., Lachenbruch, B., McCulloh, K.A., Woodruff, D.R., 2009. Xylem hydraulic safety margins in woody plants: coordination of stomatal control of xylem tension with hydraulic capacitance. Funct. Ecol. 23, 922-930. https://doi.org/10.1111/j.13652435.2009.01577.x

Méndez-Alonzo, R., Paz, H., Zuluaga, R.C., Rosell, J.A., Olson, M.E., 2012. Coordinated evolution of leaf and stem economics in tropical dry forest trees. Ecology 93, 2397-2406. https://doi.org/10.1890/11-1213.1

Nardini, A., Pedà, G., Rocca, N.L., 2012. Trade-offs between leaf hydraulic capacity and drought vulnerability: morpho-anatomical bases, carbon costs and ecological consequences. New Phytol. 196, 788-798. https://doi.org/10.1111/j.1469-8137.2012.04294.x

Niklas, K.J., Spatz, H.-C., 2004. Growth and hydraulic (not mechanical) constraints govern the scaling of tree height and mass. Proc. Natl. Acad. Sci. 101, 15661-15663. https://doi.org/10.1073/pnas.0405857101

Olson, M.E., Anfodillo, T., Rosell, J.A., Petit, G., Crivellaro, A., Isnard, S., León-Gómez, C., AlvaradoCárdenas, L.O., Castorena, M., 2014. Universal hydraulics of the flowering plants: vessel diameter scales with stem length across angiosperm lineages, habits and climates. Ecol. Lett. 17, 988-997. https://doi.org/10.1111/ele.12302

Peguero-Pina, J.J., Sancho-Knapik, D., Morales, F., Flexas, J., Gil-Pelegrín, E., 2009. Differential photosynthetic performance and photoprotection mechanisms of three Mediterranean evergreen oaks under severe drought stress. Funct. Plant Biol. 36, 453-462. https://doi.org/10.1071/FP08297

Posch, S., Bennett, L.T., 2009. Photosynthesis, photochemistry and antioxidative defence in response to two drought severities and with re-watering in Allocasuarina luehmannii. Plant Biol. 11, 83-93. https://doi.org/10.1111/j.1438-8677.2009.00245.x

Prentice, I.C., Dong, N., Gleason, S.M., Maire, V., Wright, I.J., 2014. Balancing the costs of carbon gain and water transport: testing a new theoretical framework for plant functional ecology. Ecol. Lett. 17, 82-91. https://doi.org/10.1111/ele.12211

Raschke, K., Monteith, J.L., Weatherley, P.E., 1976. How stomata resolve the dilemma of opposing priorities. Philos. Trans. R. Soc. Lond. B Biol. Sci. 273, 551-560. https://doi.org/10.1098/rstb.1976.0031

Rungwattana, K., Kasemsap, P., Phumichai, T., Kanpanon, N., Rattanawong, R., Hietz, P., 2018. Trait evolution in tropical rubber (Hevea brasiliensis) trees is related to dry season intensity. Funct. Ecol. 32, 2638-2651. https://doi.org/10.1111/1365-2435.13203

Sabot, M.E.B., Kauwe, M.G.D., Pitman, A.J., Medlyn, B.E., Verhoef, A., Ukkola, A.M., Abramowitz, G., 2020. Plant profit maximization improves predictions of European forest responses to drought. New Phytol. 226, 1638-1655. https://doi.org/10.1111/nph.16376

Sack, L., Holbrook, N.M., 2006. Leaf Hydraulics. Annu. Rev. Plant Biol. 57, 361-381. https://doi.org/10.1146/annurev.arplant.56.032604.144141

Salmon, Y., Lintunen, A., Dayet, A., Chan, T., Dewar, R., Vesala, T., Hölttä, T., 2020. Leaf carbon and water status control stomatal and nonstomatal limitations of photosynthesis in trees. New Phytol. 226, 690-703. https://doi.org/10.1111/nph.16436

Santiago, L.S., Guzman, M.E.D., Baraloto, C., Vogenberg, J.E., Brodie, M., Hérault, B., Fortunel, C., Bonal, D., 2018. Coordination and trade-offs among hydraulic safety, efficiency and drought avoidance traits in Amazonian rainforest canopy tree species. New Phytol. 218, 1015-1024. https://doi.org/10.1111/nph.15058

Scoffoni, C., Albuquerque, C., Brodersen, C.R., Townes, S.V., John, G.P., Bartlett, M.K., Buckley, T.N., McElrone, A.J., Sack, L., 2017. Outside-Xylem Vulnerability, Not Xylem Embolism, Controls 
Leaf Hydraulic Decline during Dehydration. Plant Physiol. 173, 1197-1210.

https://doi.org/10.1104/pp.16.01643

Skelton, R.P., Dawson, T.E., Thompson, S.E., Shen, Y., Weitz, A.P., Ackerly, D., 2018. Low Vulnerability to Xylem Embolism in Leaves and Stems of North American Oaks. Plant Physiol. 177, 10661077. https://doi.org/10.1104/pp.18.00103

Sperry, J.S., Love, D.M., 2015. What plant hydraulics can tell us about responses to climate-change droughts. New Phytol. 207, 14-27. https://doi.org/10.1111/nph.13354

Sperry, J.S., Venturas, M.D., Anderegg, W.R.L., Mencuccini, M., Mackay, D.S., Wang, Y., Love, D.M., 2017. Predicting stomatal responses to the environment from the optimization of photosynthetic gain and hydraulic cost. Plant Cell Environ. 40, 816-830. https://doi.org/10.1111/pce.12852

Stocker, B.D., Wang, H., Smith, N.G., Harrison, S.P., Keenan, T.F., Sandoval, D., Davis, T., Prentice, I.C., 2020. P-model v1.0: an optimality-based light use efficiency model for simulating ecosystem gross primary production. Geosci. Model Dev. 13, 1545-1581. https://doi.org/10.5194/gmd13-1545-2020

Stocker, B.D., Zscheischler, J., Keenan, T.F., Prentice, I.C., Penuelas, J., Seneviratne, S.I., 2018. Quantifying soil moisture impacts on light use efficiency across biomes. New Phytol. 20.

Tezara, W., Driscoll, S., Lawlor, D.W., 2008. Partitioning of photosynthetic electron flow between $\mathrm{CO} 2$ assimilation and $\mathrm{O} 2$ reduction in sunflower plants under water deficit. Photosynthetica 46, 127-134. https://doi.org/10.1007/s11099-008-0020-1

Venturas, M.D., Sperry, J.S., Love, D.M., Frehner, E.H., Allred, M.G., Wang, Y., Anderegg, W.R.L., 2018. A stomatal control model based on optimization of carbon gain versus hydraulic risk predicts aspen sapling responses to drought. New Phytol. 220, 836-850. https://doi.org/10.1111/nph.15333

Wang, H., Atkin, O.K., Keenan, T.F., Smith, N.G., Wright, I.J., Bloomfield, K.J., Kattge, J., Reich, P.B., Prentice, I.C., 2020. Acclimation of leaf respiration consistent with optimal photosynthetic capacity. Glob. Change Biol. 26, 2573-2583. https://doi.org/10.1111/gcb.14980

Wang, H., Prentice, I.C., Keenan, T.F., Davis, T.W., Wright, I.J., Cornwell, W.K., Evans, B.J., Peng, C., 2017. Towards a universal model for carbon dioxide uptake by plants. Nat. Plants 3, 734741. https://doi.org/10.1038/s41477-017-0006-8

Wang, Y., Sperry, J.S., Anderegg, W.R.L., Venturas, M.D., Trugman, A.T., 2020. A theoretical and empirical assessment of stomatal optimization modeling. New Phytol. 227, 311-325. https://doi.org/10.1111/nph.16572

West, G.B., Brown, J.H., Enquist, B.J., 1999. A general model for the structure and allometry of plant vascular systems. Nature 400, 4.

Wolf, A., Anderegg, W.R.L., Pacala, S.W., 2016. Optimal stomatal behavior with competition for water and risk of hydraulic impairment. Proc. Natl. Acad. Sci. 113, E7222-E7230. https://doi.org/10.1073/pnas.1615144113

Xu, X., Medvigy, D., Powers, J.S., Becknell, J.M., Guan, K., 2016. Diversity in plant hydraulic traits explains seasonal and inter-annual variations of vegetation dynamics in seasonally dry tropical forests. New Phytol. 212, 80-95. https://doi.org/10.1111/nph.14009

Zhou, S., Duursma, R.A., Medlyn, B.E., Kelly, J.W.G., Prentice, I.C., 2013. How should we model plant responses to drought? An analysis of stomatal and non-stomatal responses to water stress. Agric. For. Meteorol. 182-183, 204-214. https://doi.org/10.1016/j.agrformet.2013.05.009

Zhou, S., Zhang, Y., Williams, A.P., Gentine, P., 2019. Projected increases in intensity, frequency, and terrestrial carbon costs of compound drought and aridity events. Sci. Adv. 5, eaau5740. https://doi.org/10.1126/sciadv.aau5740

Zhou, S.-X., Medlyn, B.E., Prentice, I.C., 2016. Long-term water stress leads to acclimation of drought sensitivity of photosynthetic capacity in xeric but not riparian Eucalyptus species. Ann. Bot. 117, 133-144. https://doi.org/10.1093/aob/mcv161 


\section{Supplementary Information: Towards a unified theory of plant photosynthesis and hydraulics}

Jaideep Joshi, Benjamin D. Stocker, Florian Hofhansl, Shuangxi Zhou, Ulf Dieckmann, and Iain Colin Prentice

\section{Contents}

1 Model description 26

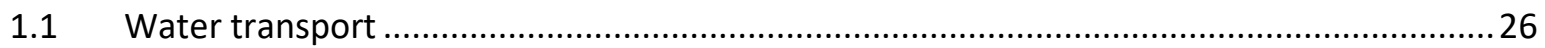

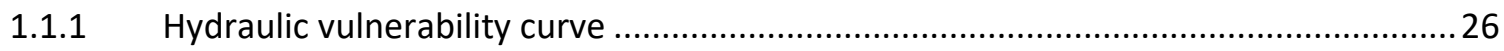

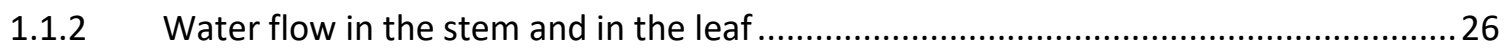

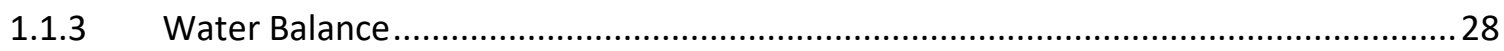

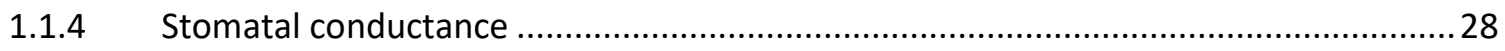

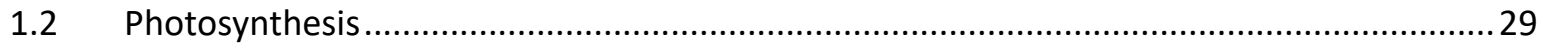

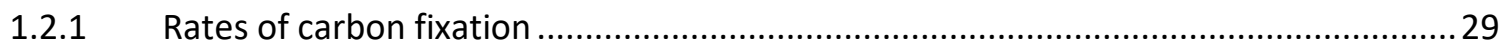

1.2.2 Photosynthetic coordination hypothesis .......................................................... 29

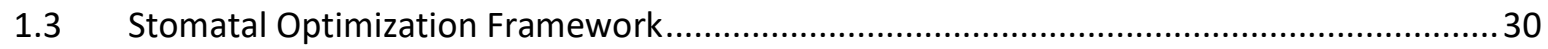

1.3.1 Analytical solution in the case of strong electron-transport limitation.....................3 31

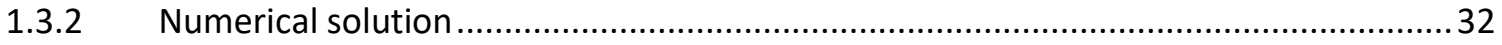

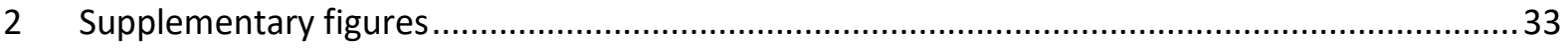

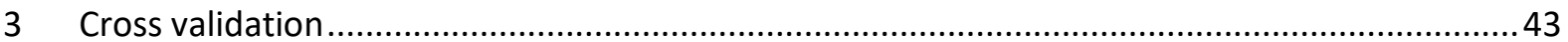

\section{Model description}

\subsection{Water transport}

\subsubsection{Hydraulic vulnerability curve}

The key aspect of the flow of liquid water through the plant's hydraulic pathways is that the conductivity of these pathways declines as water potential becomes increasingly negative. This loss of conductivity is described by a vulnerability curve of the form:

$$
\left.P(\psi)=(1 / 2)^{\left(\psi / \psi_{50}\right.}\right)^{b}
$$

So that the conductivity of the pathway as a function of water potential is described by $K(\psi)=$ $K_{0} P(\psi)$.

\subsubsection{Water flow in the stem and in the leaf}

\subsubsection{Water flow through a general conducting pathway}

In general, the potential drop across a small cross-section of any conductive pathway in the plant due to a flow rate $Q$ can be written using Darcy's law: 


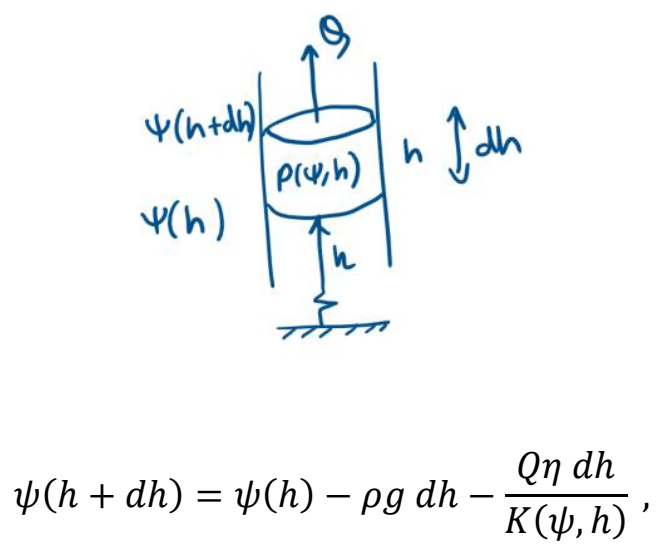

where $K^{-1}(\psi, h)$ is the resistance per unit length to water flow at location $h$ with water potential $\psi(h)$. This gives us a general equation of water flow through any conducting pathway whose conductivity varies with water potential:

$$
\frac{d \psi}{d h}=-\rho g-\frac{\eta Q}{K_{0}(h) P(\psi, h)}
$$

where $\psi$ is the water potential at a distance $h$ from the starting point, $Q$ is the flux of water through the pathway, $\eta$ is the viscosity of water, $g$ is the component of gravity in the direction of the flow, $K_{0}$ is the conductivity of the pathway at 0 water potential. $K_{0}$ and $P$ may depend on $h$ (other than through $\psi$ ) due to structural variations, such as variation in the vessel geometry with height (vessel tapering).

\subsubsection{Flow through the stem xylem}

Water is conducted through the stem by interconnected xylem vessels. The conductivity of a single vessel with length $l_{v}$ and radius $r_{v}$ is given by the Hagen-Poiseuille equation:

$$
K_{\mathrm{v}}=\frac{\pi r_{\mathrm{v}}^{4}}{8 l_{\mathrm{v}}}
$$

If the sapwood has a density $\rho_{\mathrm{v}}$ of vessels, their conductance will add up (as the vessels are in parallel). The conductivity of a section of sapwood of unit length per unit area (sapwood permeability) would then be

$$
K_{\mathrm{S}}=\frac{\pi \rho_{\mathrm{v}} r_{\mathrm{v}}^{4}}{8}
$$

For typical vessel characteristics (Choat et al., 2005): $\rho_{\mathrm{v}}=217 \mathrm{~mm}^{-2}, r_{\mathrm{v}}=15.25 \mu \mathrm{m}$, which gives a theoretical conductivity to be $K_{\mathrm{s}}=\pi \rho_{\mathrm{v}} r_{\mathrm{v}}^{4} / 8=4.6 \times 10^{-12} \mathrm{~m}^{2}$.

If we ignore gravitational and xylem tapering effects, we can solve Eq. S1 for the stem to express $Q$ as:

$$
Q=-\frac{K_{s} v_{H}}{H \eta} \int_{\psi_{s}}^{\psi_{p}} P_{x}(\psi) d \psi
$$

where the subscripts $s$ and $p$ represent the soil and the end of the vein in the leaf respectively, $H$ is plant height, and $P_{\mathrm{x}}(\psi)$ represents the vulnerability curve for the stem (and leaf) xylem. Xylem vulnerability is largely due to cavitation. Since $Q$ is expressed as the flux of water per unit leaf area, 
we multiply the sapwood specific conductivity by the Huber Value $\left(v_{\mathrm{H}}\right)$ to get the conductivity per unit leaf area.

\subsubsection{Flow through outside xylem pathways}

Once the water exits the xylem at the end of the vein, it must pass through bundle sheath cells and several layers of spongy mesophyll cells before reaching the stomata, from where it vaporizes from the cell walls and out into the atmosphere. These outside-xylem pathways offer much larger resistance to water flow compared to xylem, and lose conductivity much faster than xylem, making the leaf the hydraulic bottleneck in the flow of water.

We can represent the sum total flow through all the different outside-xylem pathways (through the cell walls and cell mesophyll) in the same way as the flow through the stem,

$$
Q=-\frac{K_{l}}{\Delta L \eta} \int_{\psi_{p}}^{\psi_{l}} P_{o x}(\psi) d \psi
$$

where $K_{1}$ is the conductivity of the leaf per unit leaf area, $\Delta L$ is the path length that water must traverse outside the xylem, and the subscript $l$ represents the leaf (more accurately, the endpoint of the hydraulic pathway, near the stomatal cells). The path length $\Delta L$ depends on the leaf thickness (LMA) and the vein length per unit leaf area (VLA). For brevity, we henceforth refer to $P_{\text {ox }}()$ as simply $P()$.

\subsubsection{Water Balance}

Ignoring storage and capacitance effects, this flow $Q$ must equal transpiration through leaves $E=$ $1.6 g_{\mathrm{s}} D$ to satisfy water balance:

$$
Q=-\frac{K_{s} v_{H}}{H \eta} \int_{\psi_{s}}^{\psi_{p}} P_{x}(\psi) d \psi=-\frac{K_{l}}{\Delta L \eta} \int_{\psi_{p}}^{\psi_{l}} P(\psi) d \psi=1.6 g_{s} D
$$

The potential drop across the xylem and outside-xylem pathways respectively are $\Delta \psi_{x}$ and $\Delta \psi_{o x}$ respectively, so that the soil-to-leaf potential difference is $\Delta \psi=\Delta \psi_{x}+\Delta \psi_{o x}$. For brevity, let us we club the net conductivity of the stem and leaf into single variables:

$$
Q=-\frac{K_{\mathrm{S}}}{\eta} \int_{\psi_{\mathrm{s}}}^{\psi_{\mathrm{p}}=\psi_{\mathrm{s}}-\Delta \psi_{\mathrm{x}}} P_{\mathrm{x}}(\psi) d \psi=-\frac{K_{\mathrm{L}}}{\eta} \int_{\psi_{\mathrm{p}}}^{\psi_{\mathrm{p}}-\Delta \psi_{\mathrm{ox}}} P(\psi) d \psi=1.6 g_{\mathrm{s}} D
$$

Given $\Delta \psi$, this gives us three nonlinear simultaneous equations which can be solved iteratively for $g_{\mathrm{s}}, \Delta \psi_{\mathrm{x}}$ and $\Delta \psi_{\mathrm{ox}}$. However, if we make a simplifying assumption as described below, we can solve for $g_{s}$ analytically.

\subsubsection{Stomatal conductance}

Assuming that leaf is the hydraulic bottleneck, $\Delta \psi_{\mathrm{x}} \approx 0$, and $\psi_{\mathrm{p}} \approx \psi_{\mathrm{s}}$. With these simplifications, we can express $g_{s}$ in terms of $\Delta \psi\left(\approx \Delta \psi_{o x}\right)$ as

$$
g_{s}=-\frac{K}{1.6 D \eta} \int_{\psi_{s}}^{\psi_{s}-\Delta \psi} P(\psi) d \psi
$$


where, for brevity, we have dropped the subscript $L$ from $K$ since we are now only considering one hydraulic pathway. We further note that due to the water balance condition, $g_{\mathrm{s}}$ is independent of $\chi$.

\subsection{Photosynthesis}

\subsubsection{Rates of carbon fixation}

The rate of photosynthesis is the minimum of the electron transport limited and the carboxylation limited rates.

The carboxylation-limited rate is given by the Cowan-Farquhar biochemical model:

$$
A_{\mathrm{c}}=V_{\mathrm{cmax}} \frac{c_{\mathrm{i}}-\Gamma^{*}}{c_{\mathrm{i}}+K_{\mathrm{M}}}-R_{d}
$$

where $R_{\mathrm{d}}$ is dark respiration, which is assumed to be proportional to $V_{\mathrm{cmax}}$.

$$
R_{\mathrm{d}}=b_{\mathrm{r}} V_{\mathrm{cmax}}
$$

Therefore, $A_{\mathrm{c}}$ can be written as

$$
A_{c}=V_{c \max } \frac{c_{i}\left(1-b_{r}\right)-\left(\Gamma^{*}+b_{r} K_{M}\right)}{c_{i}+K_{M}}
$$

The electron transport limited rate is given by

$$
A_{\mathrm{j}}=A_{\mathrm{Jm}} \frac{c_{\mathrm{i}}-\Gamma^{*}}{c_{\mathrm{i}}+2 \Gamma^{*}}-R_{\mathrm{d}}
$$

where

$$
A_{J m}=\frac{\phi_{0} I_{a b s}}{\sqrt{1+\left(\frac{4 \phi_{0} I_{a b s}}{J_{\max }}\right)^{2}}}
$$

Inverting the above relation, we can express $J_{\max }$ in terms of $A_{\mathrm{Jm}}$ as

$$
J_{\max }=\frac{4 \phi_{0} I_{a b s}}{\sqrt{\left(\frac{\phi_{0} I_{a b s}}{A_{J m}}\right)^{2}-1}}
$$

The rate of $\mathrm{CO}_{2}$ fixation must also equal the rate of $\mathrm{CO}_{2}$ uptake by the plant:

$$
A=g_{s} c_{a}(1-\chi)
$$

\subsubsection{Photosynthetic coordination hypothesis}

We assume the carboxylation-limited and electron-transport-limited assimilation rates are equal.

$$
A=A_{\mathrm{c}}=A_{\mathrm{j}}
$$

Therefore 


$$
V_{\mathrm{cmax}} \frac{c_{i}-\Gamma^{*}}{c_{i}+K_{M}}-R_{d}=A_{J m} \frac{c_{i}-\Gamma^{*}}{c_{i}+2 \Gamma^{*}}-R_{d}
$$

giving

$$
V_{c \max }=A_{J m} \frac{c_{i}+K_{M}}{c_{i}+2 \Gamma^{*}}
$$

Therefore, $A_{j}$ can be rewritten as

$$
A_{j}=A_{J m} \frac{c_{i}\left(1-b_{r}\right)-\left(\Gamma^{*}+b_{r} K_{M}\right)}{c_{i}+2 \Gamma^{*}}
$$

Equating Eq. S8 and Eq. S10, $A_{J m}$ can be expressed in terms of $\chi$ as

$$
A_{J m}=g_{s} c_{a} \frac{(1-\chi)\left(\chi c_{a}+2 \Gamma^{*}\right)}{\chi c_{a}\left(1-b_{r}\right)-\left(\Gamma^{*}+b_{r} K_{M}\right)}
$$

This gives us an expression for $J_{\max }$ in terms of $g_{s}$ and $\chi$.

\subsection{Stomatal Optimization Framework}

We assume that plants maximize profit $(F)$ defined as

$$
F=A_{j}-\alpha J_{\max }-\gamma \Delta \psi^{2}
$$

Where each term is a function of the two independent variables $\chi$ and $\Delta \psi$.

$$
F=g_{s} c_{a}(1-\chi)-\alpha J_{\max }-\gamma \Delta \psi^{2}
$$

To solve the optimality condition, we set the gradient of the profit function to zero.

$$
\begin{aligned}
& \frac{\partial F}{\partial \chi}=-g_{s} c_{a}-\alpha \frac{\partial J_{\max }}{\partial A_{J m}} \frac{\partial A_{J m}}{\partial \chi}-0=0 \\
& \frac{\partial F}{\partial \Delta \psi}=\frac{\partial g_{s}}{\partial \Delta \psi} c_{a}(1-\chi)-\alpha \frac{\partial J_{\max }}{\partial A_{J m}} \frac{\partial A_{J m}}{\partial \Delta \psi}-2 \gamma \Delta \psi=0
\end{aligned}
$$


The four derivatives required in the above equations are as follows:

$$
\begin{gathered}
\frac{\partial J_{\max }}{\partial A_{J m}}=\frac{4\left(\phi_{0} I_{a b s}\right)^{3}}{\left(\left(\phi_{0} I_{a b s}\right)^{2}-A_{J m}^{2}\right)^{3 / 2}} \\
\frac{\partial A_{J m}}{\partial \chi}=g_{s} c_{a}\left(b_{r} \frac{2 \frac{\Gamma^{*}}{c_{a}}\left(\frac{K_{M}}{c_{a}}+1\right)+\frac{K_{M}}{c_{a}}(2 \chi-1)+\chi^{2}}{\left(\delta\left(\frac{K_{M}}{c_{a}}+\chi\right)+\frac{\Gamma^{*}}{c_{a}}-\chi\right)^{2}}\right. \\
\left.\quad-\frac{\left(\chi-\frac{\Gamma^{*}}{c_{a}}\right)^{2}+3 \frac{\Gamma^{*}}{c_{a}}\left(1-\frac{\Gamma^{*}}{c_{a}}\right)}{\left(\delta\left(\frac{K_{M}}{c_{a}}+\chi\right)+\frac{\Gamma^{*}}{c_{a}}-\chi\right)^{2}}\right) \\
\frac{\partial A_{J m}}{\partial \Delta \psi}=\frac{\partial g_{s}}{\partial \Delta \psi} c_{a} \frac{(1-\chi)\left(\chi c_{a}+2 \Gamma^{*}\right)}{\chi c_{a}\left(1-b_{r}\right)-\left(\Gamma^{*}+b_{r} K_{M}\right)} \\
\frac{\partial g_{s}}{\partial \Delta \psi}=\frac{\partial}{\partial \Delta \psi}\left(-\frac{K}{1.6 D \eta} \int_{\psi_{s}}^{\psi_{s}-\Delta \psi} P(\psi) d \psi\right)=\frac{K}{1.6 D \eta} P\left(\psi_{s}-\Delta \psi\right)
\end{gathered}
$$

Substituting the derivatives from Eq. S13 into Eq. S12, the roots of the gradient can be computed numerically.

\subsubsection{Analytical solution in the case of strong electron-transport limitation}

Optimal $\chi$ has a closed form solution in the special case where $J_{\max } \ll 4 \phi_{0} I_{a b s}$, i.e. when $4 A_{J m} \approx$ $J_{\text {max }} \cdot \operatorname{In}$ that case,

$$
\frac{\partial J_{\max }}{\partial A_{J m}}=4
$$

and thus,

$$
\frac{\partial F}{\partial \chi}=-g_{s} c_{a}-4 \alpha \frac{\partial A_{J m}}{\partial \chi}=0
$$

This is a quadratic in $\chi$, giving

$$
\chi^{*}=\frac{\left(1-4 \alpha-b_{r}\right)\left(b_{r} K_{M}+\frac{\Gamma^{*}}{c_{a}}\right)+\sqrt{4 \alpha\left(1-4 \alpha-b_{r}\right)\left(3 \frac{\Gamma^{*}}{c_{a}}-\delta\left(2 \frac{\Gamma^{*}}{c_{a}}+K_{M}\right)\right)\left(1-\frac{\Gamma^{*}}{c_{a}}-b_{r}\left(1+K_{M}\right)\right)}}{\left(1-b_{r}\right)\left(1-4 \alpha-b_{r}\right)}
$$

In the absence of dark respiration $\left(b_{r}=0\right)$, this simplifies to:

$$
\chi^{*}=\frac{\frac{\Gamma^{*}}{c_{a}}(1-4 \alpha)+\sqrt{12 \alpha(1-4 \alpha) \frac{\Gamma^{*}}{c_{a}}\left(1-\frac{\Gamma^{*}}{c_{a}}\right)}}{1-4 \alpha}
$$




\subsubsection{Numerical solution}

In the numerical version of the model, it is more convenient to express all quantities in terms of $J_{\max }$ and $\Delta \psi$. Plotting profit as a function of $J_{\max }$ and $\Delta \psi$, we can see that it has a clear maximum. However, there is no minimum in the summed costs (normalized by $A$ ) alone.
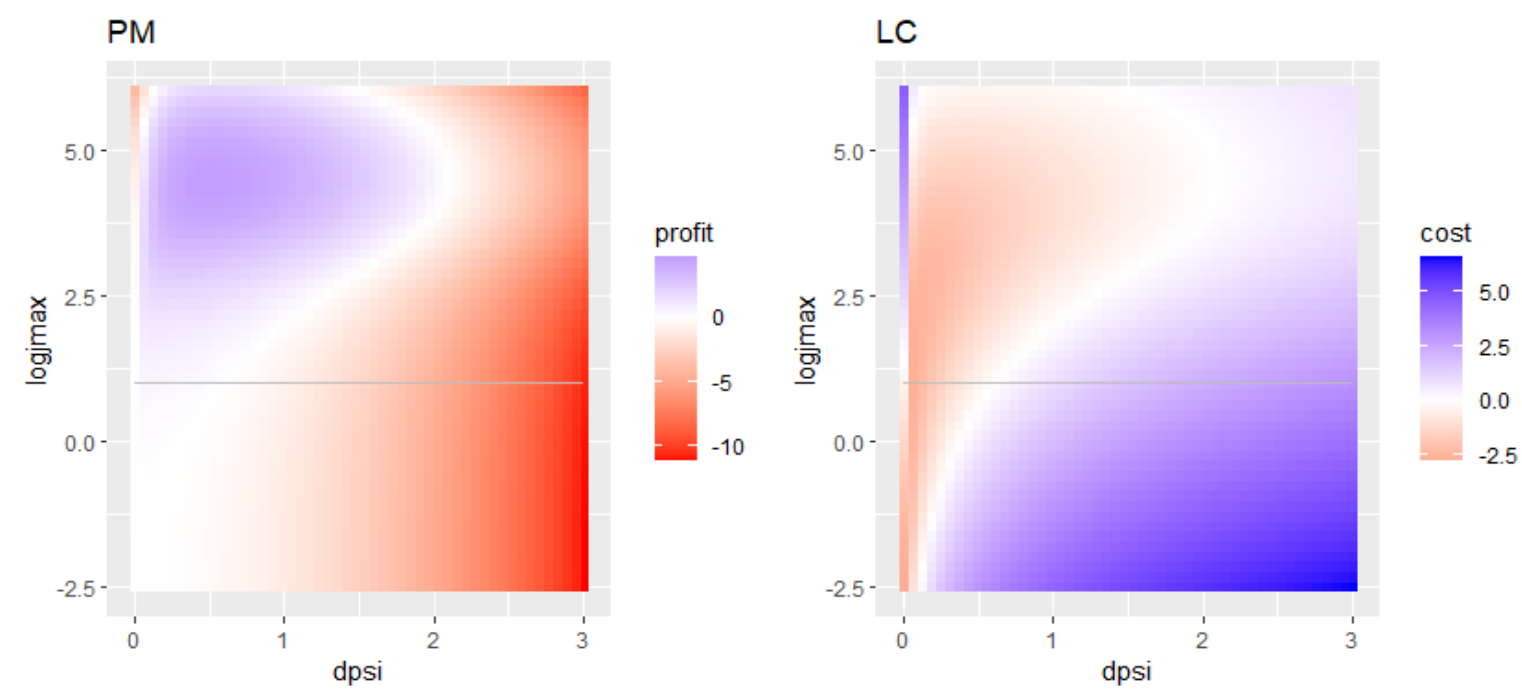

Fig. Profit as a function of the two state variables $\left(\Delta \psi\right.$ and $\left.J_{\max }\right)$. (PM) The profit function has a maximum, allowing an optimal solution to exist. (LC) The costs alone $\left(\alpha J_{\max }+\gamma \Delta \psi^{2}\right) / A$ do not have a minimum, which is why the least-costs hypothesis does not work in our model. 


\section{Supplementary figures}
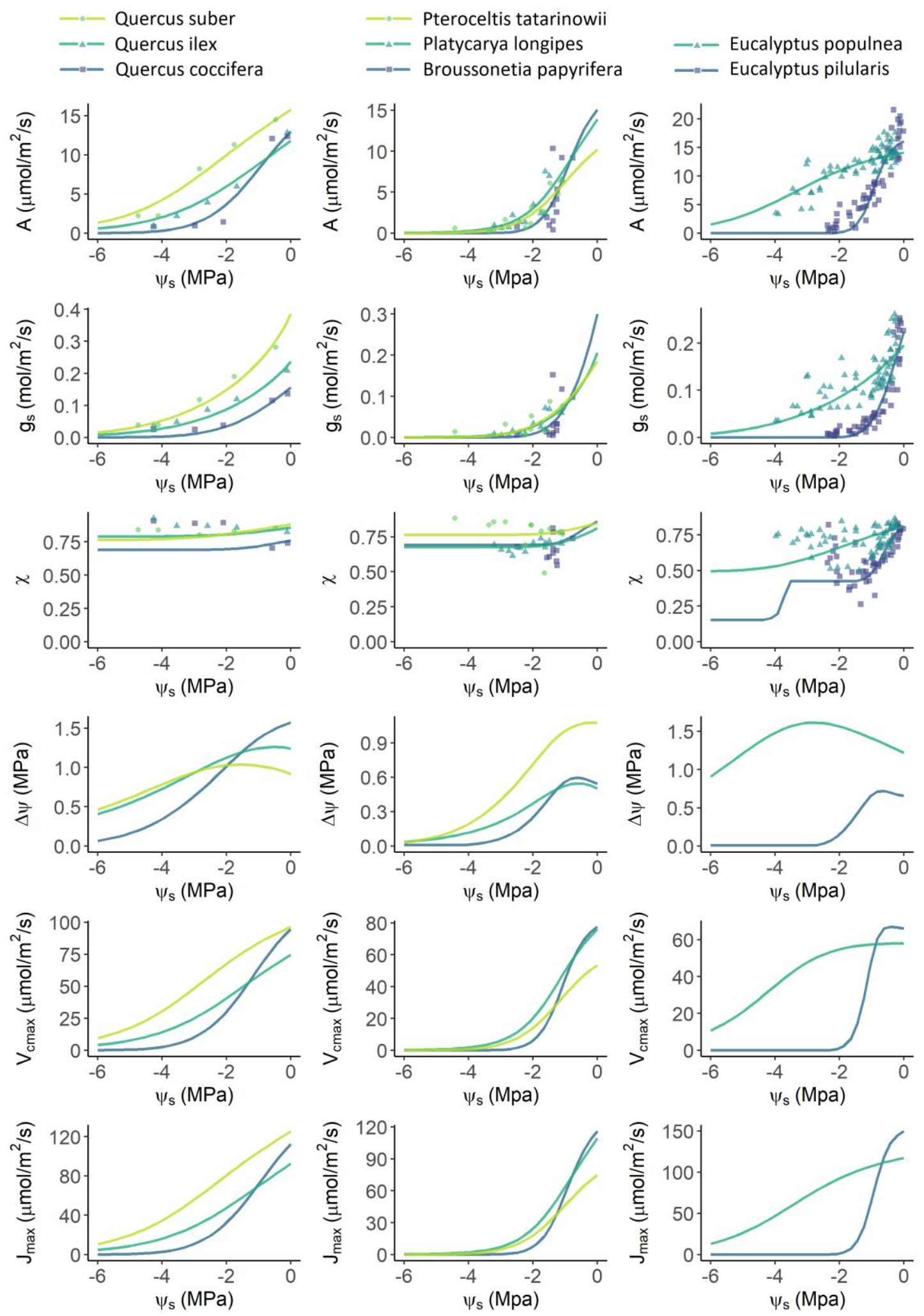

Fig. S1. Predicted and observed responses of different species to soil dry-down. This figure shows all species on the lines of Fig. 2 in the main text. Part 1/3. 

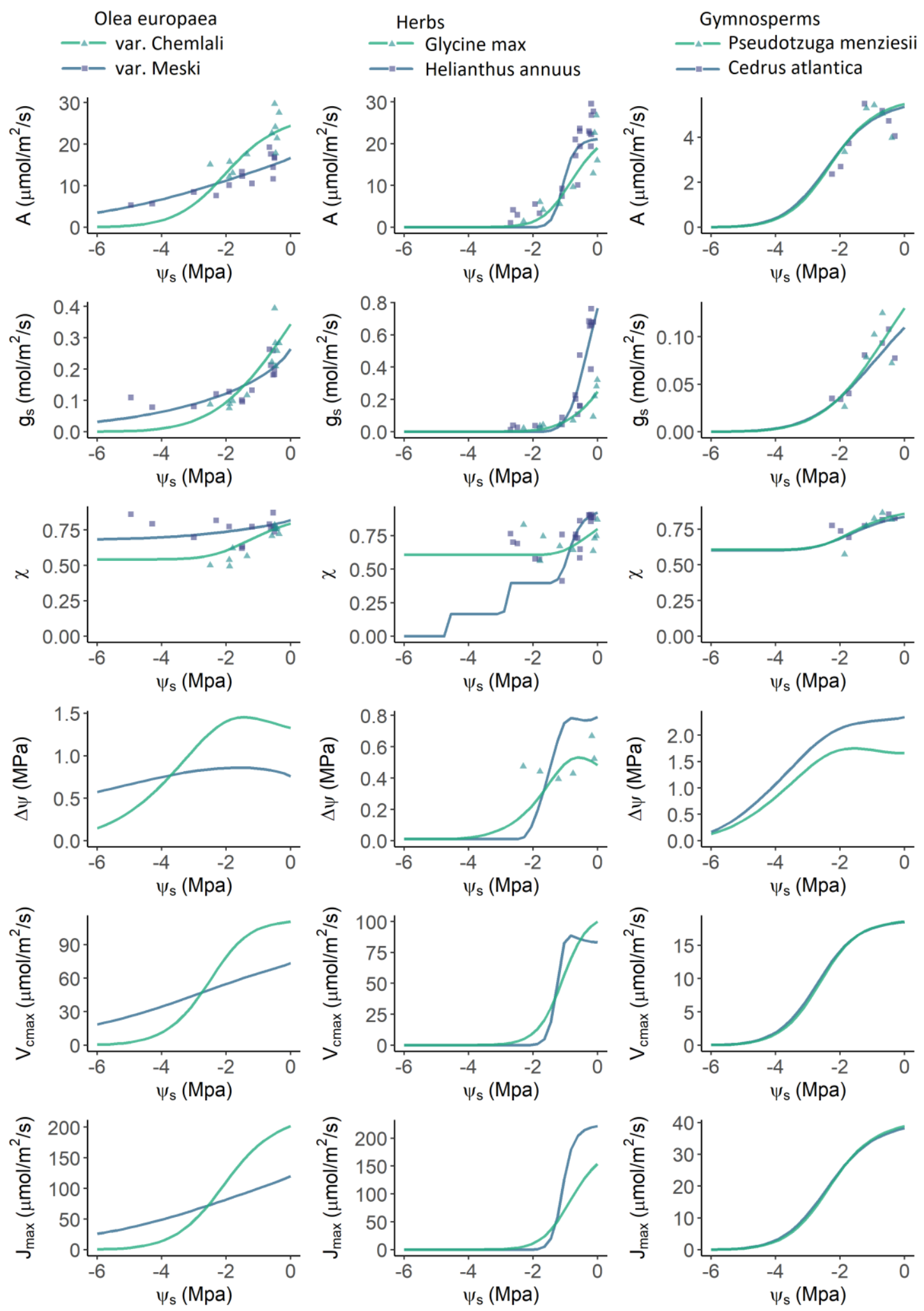

Fig. S2. Predicted and observed responses of different species to soil dry-down. This figure shows all species on the lines of Fig. 2 in the main text. Part 2/3. 

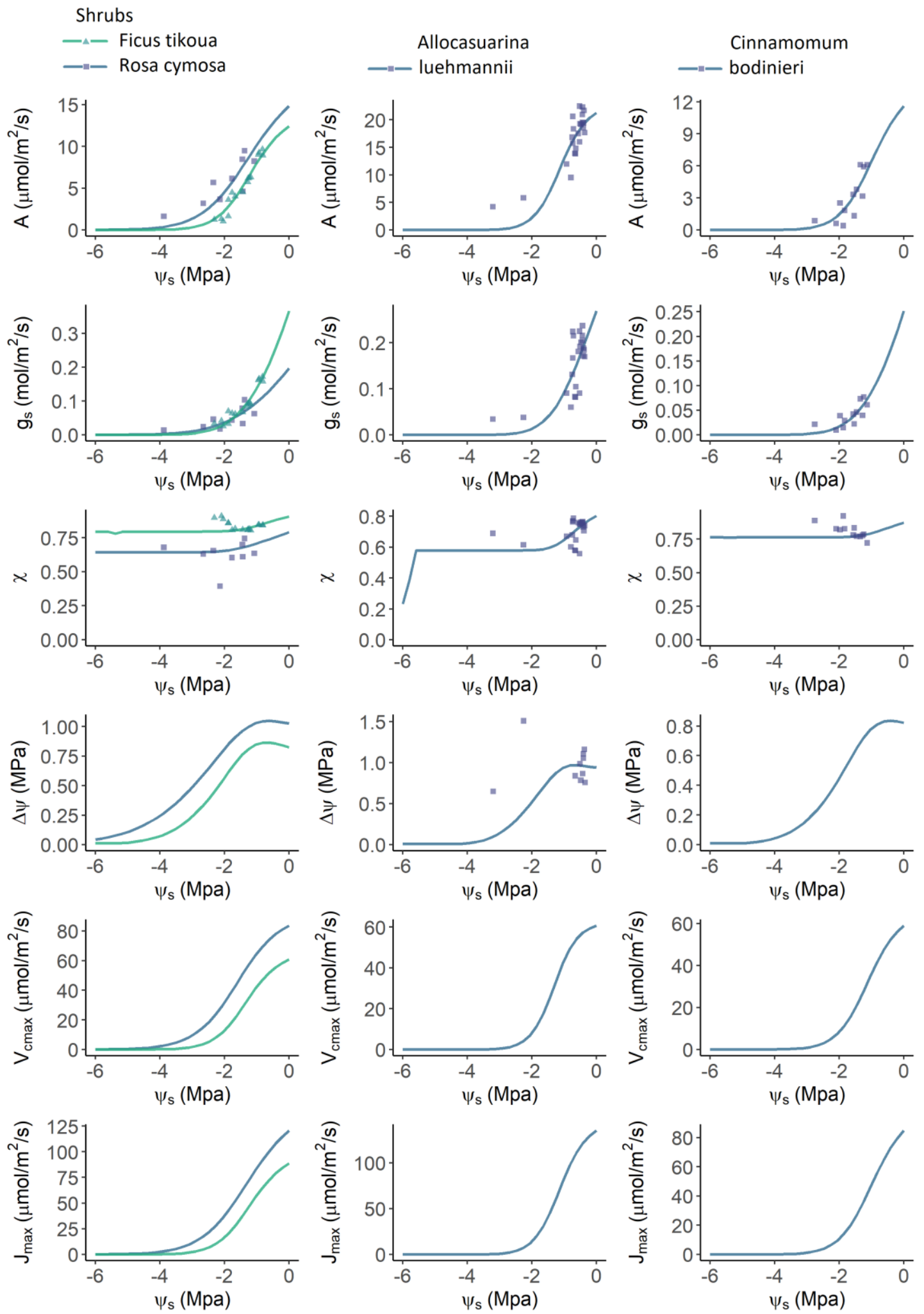

Fig. S3. Predicted and observed responses of different species to soil dry-down. This figure shows all species on the lines of Fig. 2 in the main text. Part 3/3. 

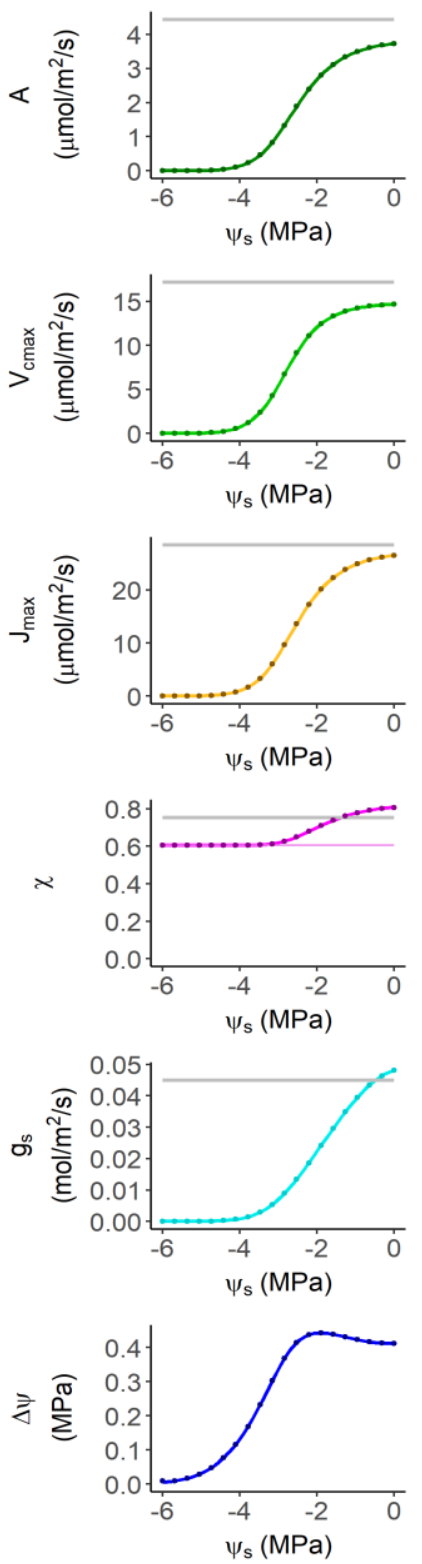
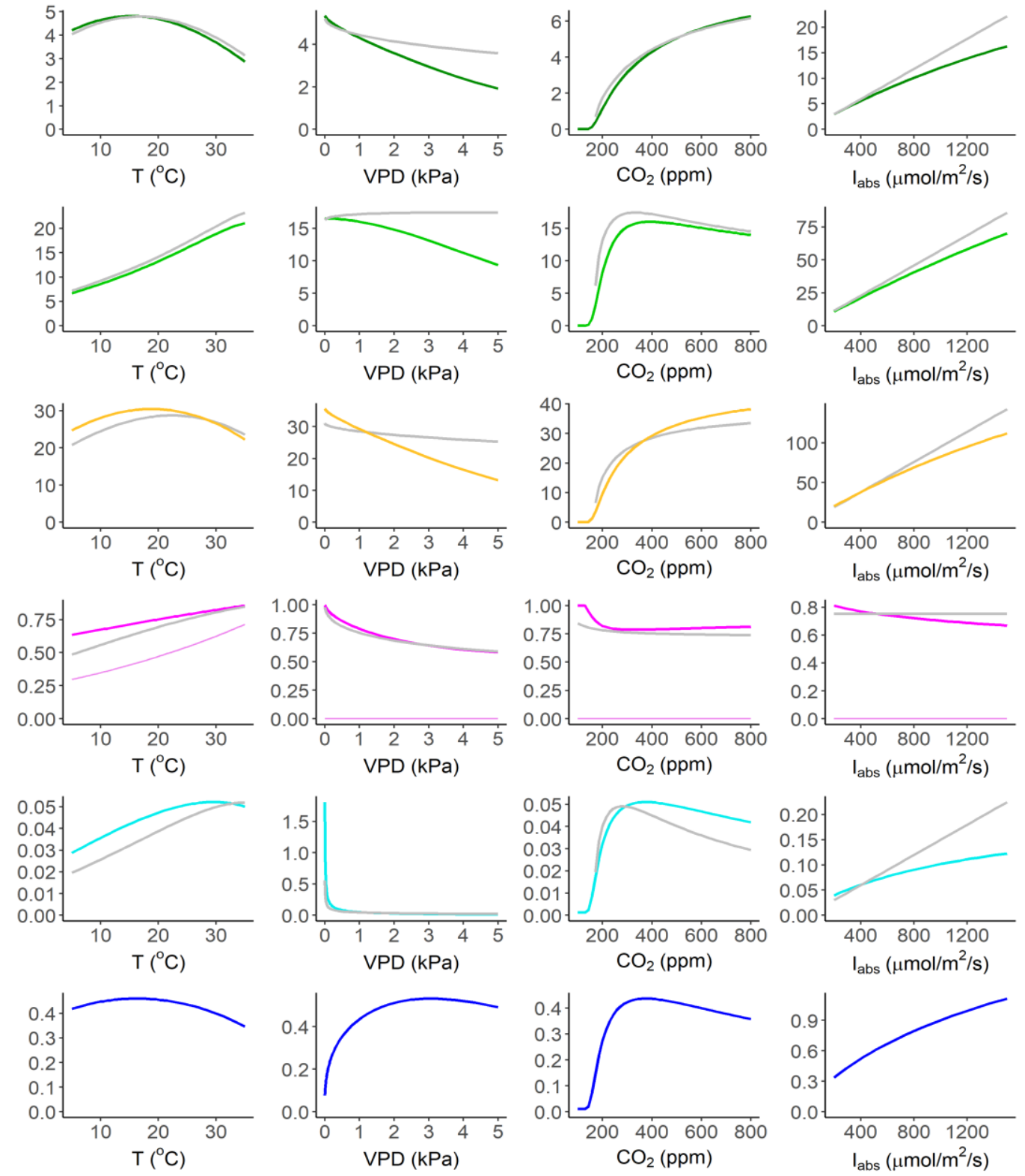

Fig. S4. Predicted responses to atmospheric variables from our model (coloured lines) closely resemble those of Wang et al. (2017) (grey lines). The Wang et al. (2017) model lacks an explicit representation of hydraulics, and uses only one cost parameter $\beta$. To facilitate comparison of our model with theirs, we set $\beta=146$ in their model, and parameterize our model with an "average" plant with the following parameters: $K=0.3 \times 10^{-16} \mathrm{~m}^{2}, \psi_{50}=-2 \mathrm{Mpa}, b=2, \alpha=0.1$, and $\gamma=$ 4. Also shown is the comparison of the semi-analytical (lines) and numerical (points) solutions to our model (leftmost column). Thin coloured lines in the first two columns represent the strongly $J_{\text {max }^{-}}$ limited value of $\chi$, as calculated from Eq. S14. Columns 3-5 use the numerical solution. 

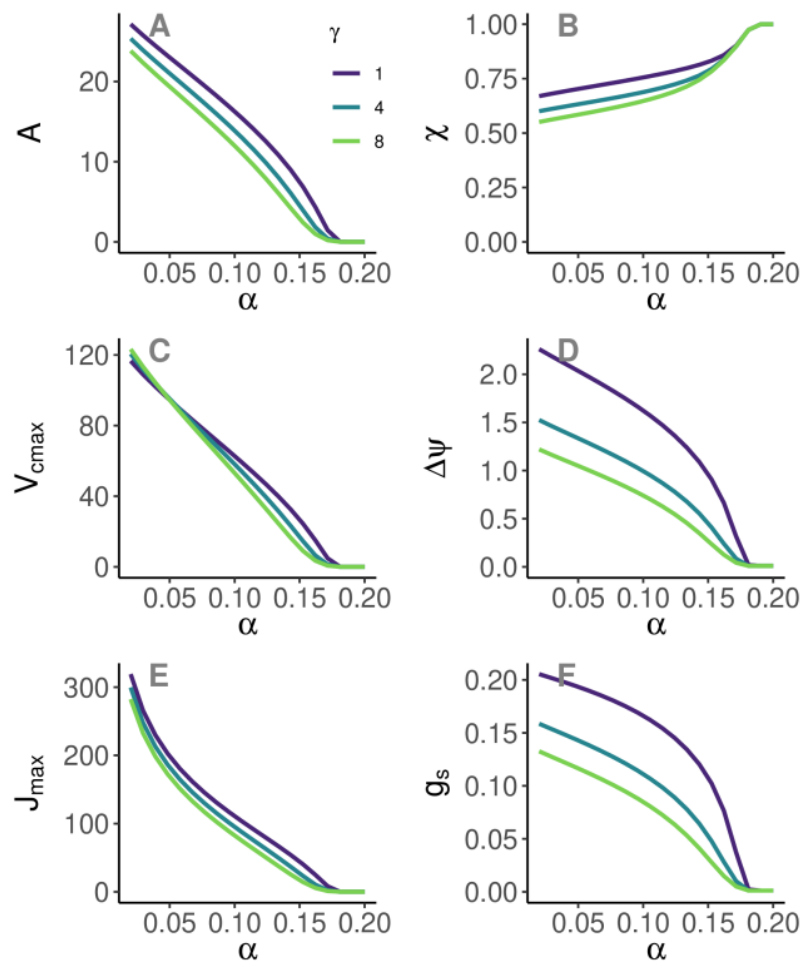

Fig. S5. The influence of costs. All variables depend strongly on the cost of photosynthetic capacity $(\alpha)$ whereas only $g_{s}$ and $\Delta \psi$ depend on the hydraulic costs $(\gamma)$. The hydraulic exploitation hypothesis works through this effect of the hydraulic cost on $\Delta \psi$. The following parameters were used in this plot: $T=25^{\circ} C, I_{a b s}=210 \mu \mathrm{mol} \mathrm{m}^{-2} \mathrm{~s}^{-1}, \mathrm{VPD}=1 \mathrm{kPa}, \mathrm{CO}_{2}=400 \mathrm{ppm}, \psi_{s}=0, b_{r}=0, K=$ $0.3 \times 10^{-16} \mathrm{~m}^{2}, \psi_{50}=-2 \mathrm{Mpa}, b=2$. 

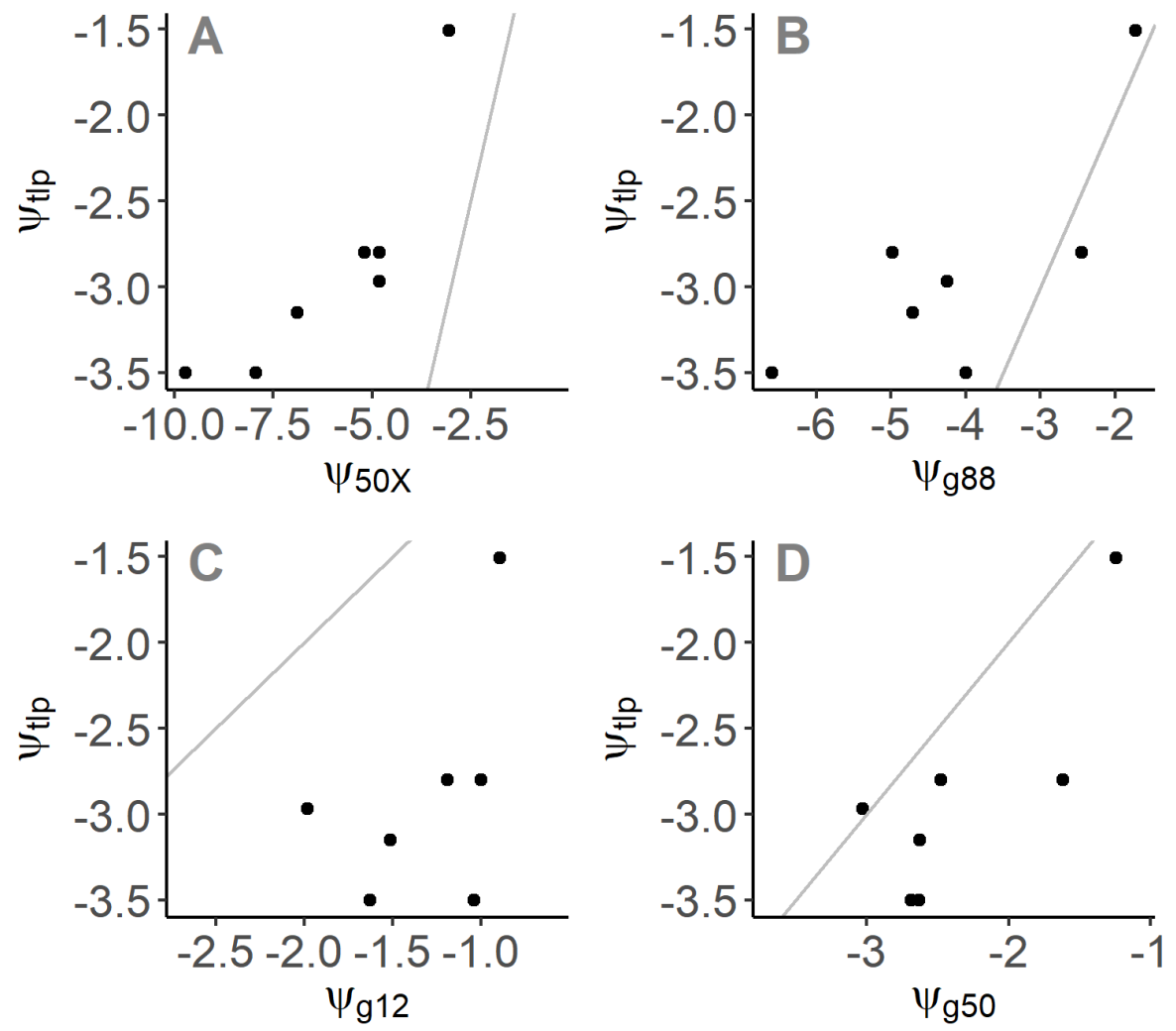

Fig. S6. Turgor loss point and stomatal closure. The relationship between turgor loss point with (A) xylem vulnerability, (B) stomatal closure point, (C) stomatal closure initiation point, and (D) point of $50 \%$ stomatal closure. Grey lines are 1:1 lines. Turgor loss occurs at a point after $50 \%$ stomatal closure, but often before full ( $88 \%$ ) stomatal closure, and well before the xylem vulnerability point. 


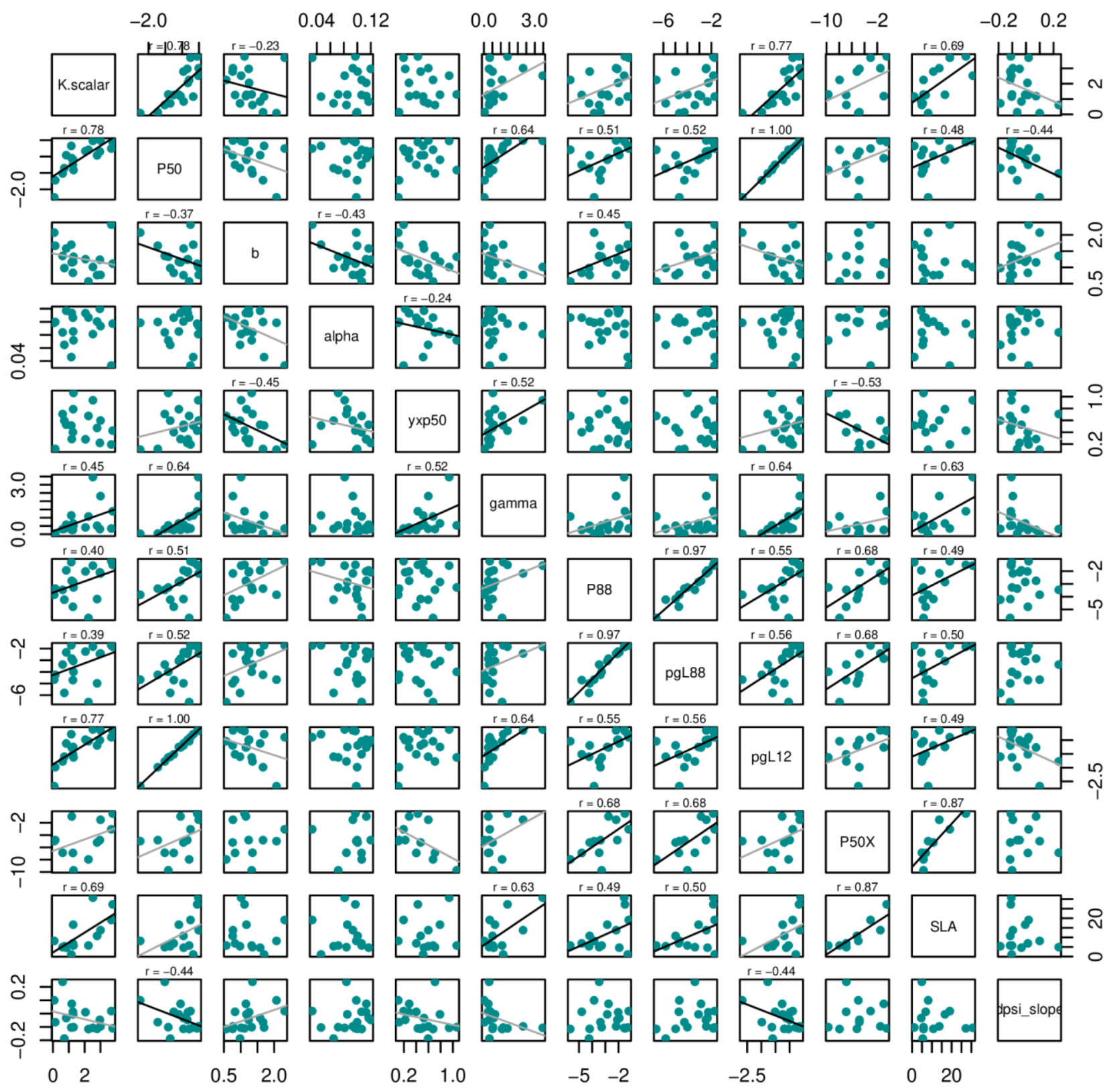

Fig. S7. Hydraulic strategies. Partial correlation plot between different fitted and observed traits shows that the strong relationships between different traits could be used to reduce the number of model parameters. Specifically, both $K$ and $b$ are significantly related to $\psi_{50}$, which may allow us to eliminate them. Furthermore, $\alpha$ is related to $\gamma$ and $\psi_{50}$, and $\gamma$ in turn is strongly (but non-linearly) related to $\psi_{50}$. Therefore, we could in principle calibrate the mode with just one parameter $\psi_{50}$. Furthermore, since $\psi_{50 X}$ is correlated to $\psi_{88}$, which in turn can be calculated from $\psi_{50}$ and $b$, the model could also be parameterized with $\psi_{50 X}$, which is more readily available in the literature. Black lines are regression lines where the fit has a $p$-value of $<0.05$, whereas grey lines are regression lines with a $p$-values of $<0.1$. No regression lines are drawn where there is no significant linear relationship between the two variables. 

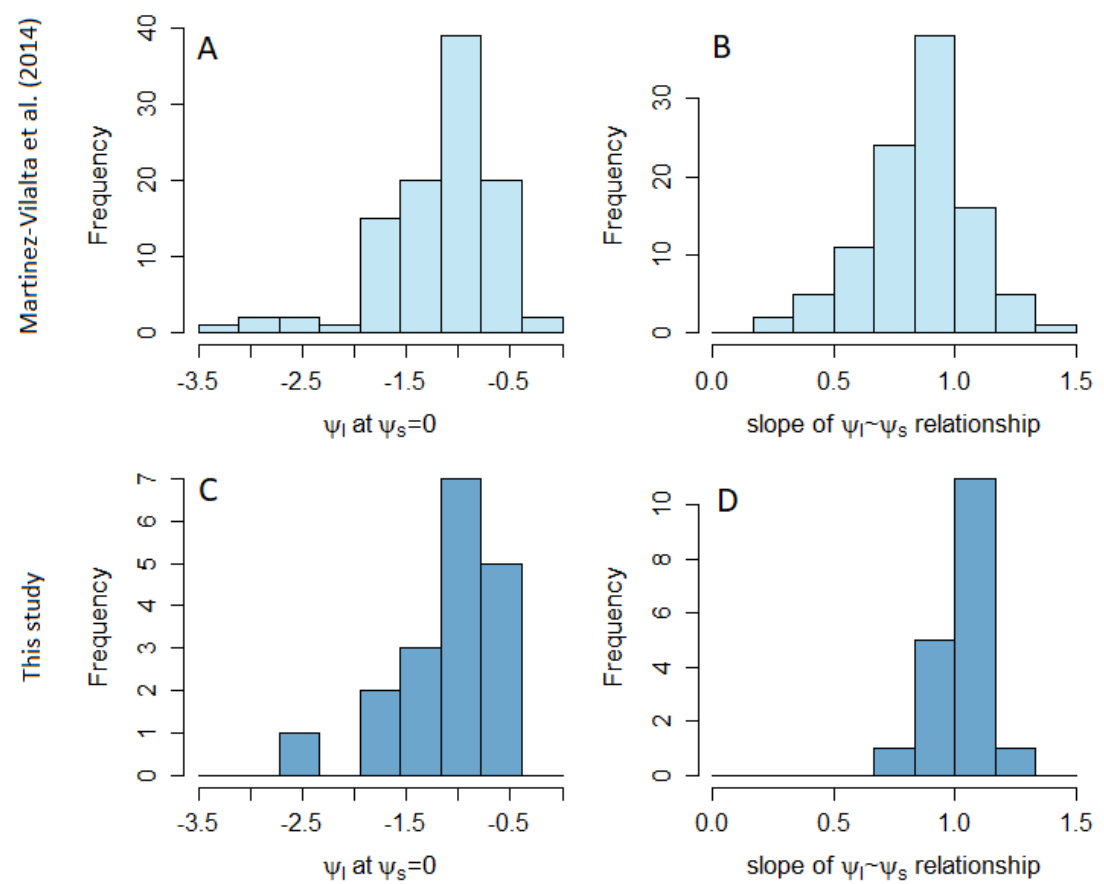

Fig. S8. Distribution of hydraulic strategies. In our model, the parameter $b$ allows us to change the hydraulic strategy of the species, i.e., its position along the isohydric-anisohydric spectrum. A slope of $<0$ represents an extreme isohydric species, in which leaf water potential stays constant. A slope of 1 represents an iso-hydrodynamic species, which maintains a constant water potential difference. A slope of $>1$ represents an anisohydric species. The distribution of hydraulic strategies among the 18 species in our model (D) is broadly consistent with larger scale data (B) obtained from MartinezVilalta et al (2014). Similarly, the normal operating leaf water potentials (under wet conditions) obtained from our model (C) are also distributed similarly to broader observed values (A). 


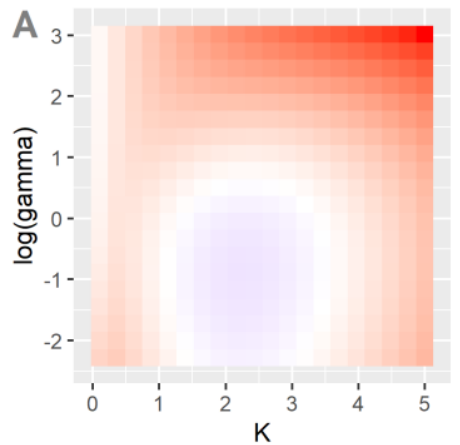

$B_{3}$.

WP profit

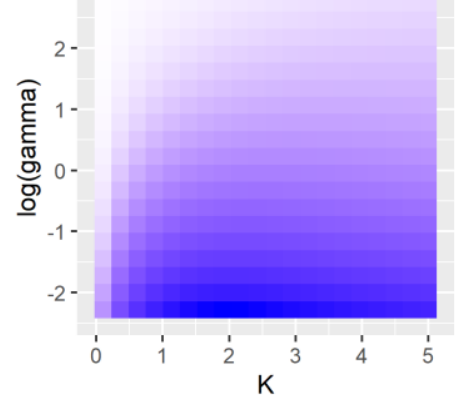

(out_hydraulics_dpsi)

0.0

$-0.4$

$-0.8$

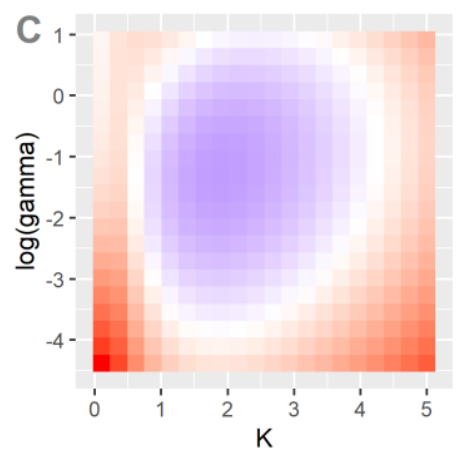

$D_{1}$

WP profit

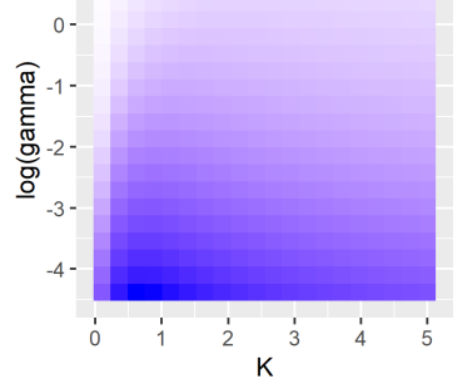

(out_hydraulics_dpsi)
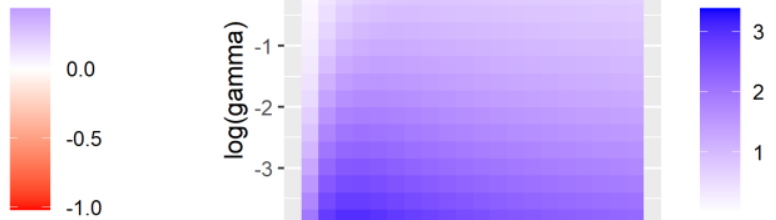

Fig. S9. Trait adaptation. Whole-plant profit $(0.2 F-0.5 \Delta \psi-0.4 K)(\mathrm{A}-\mathrm{C})$ and corresponding $\Delta \psi$ (B,D) as a function of $\gamma$ and $K$, for $\psi_{50}=-0.7$ (top row) and $\psi_{50}=-2$ (bottom row). Optimal $\gamma$ and $K$ are higher and optimal $\Delta \psi$ is lower for less negative values of $\psi_{50}$. This provides a basis for the leaf-hydraulic efficiency hypothesis via longer-term whole-plant optimality considerations, and reproduces qualitative patterns similar to Fig. 5B,D. 


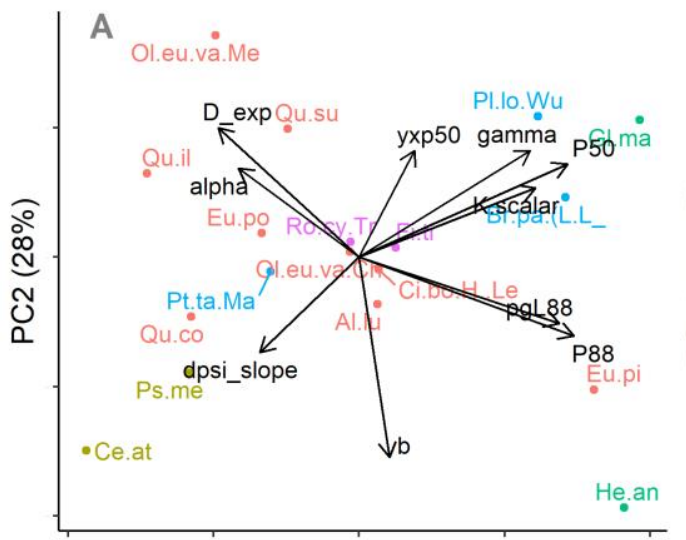

PC1 $(35.6 \%)$

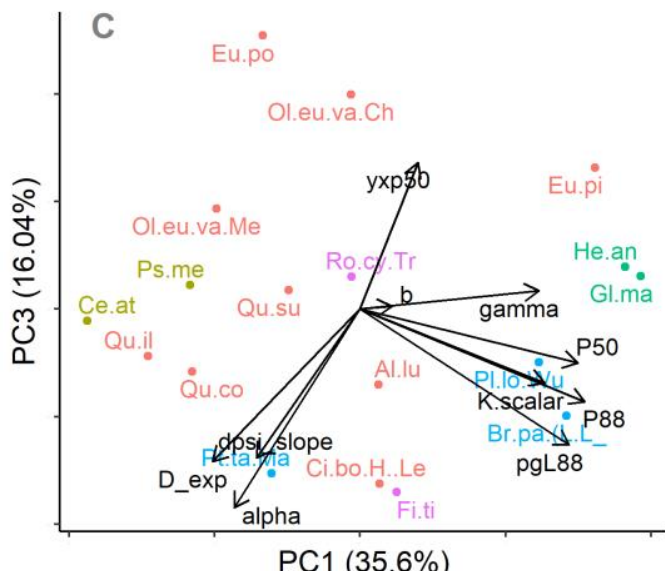

B -Eu.po

Ol.eu.va.Ch
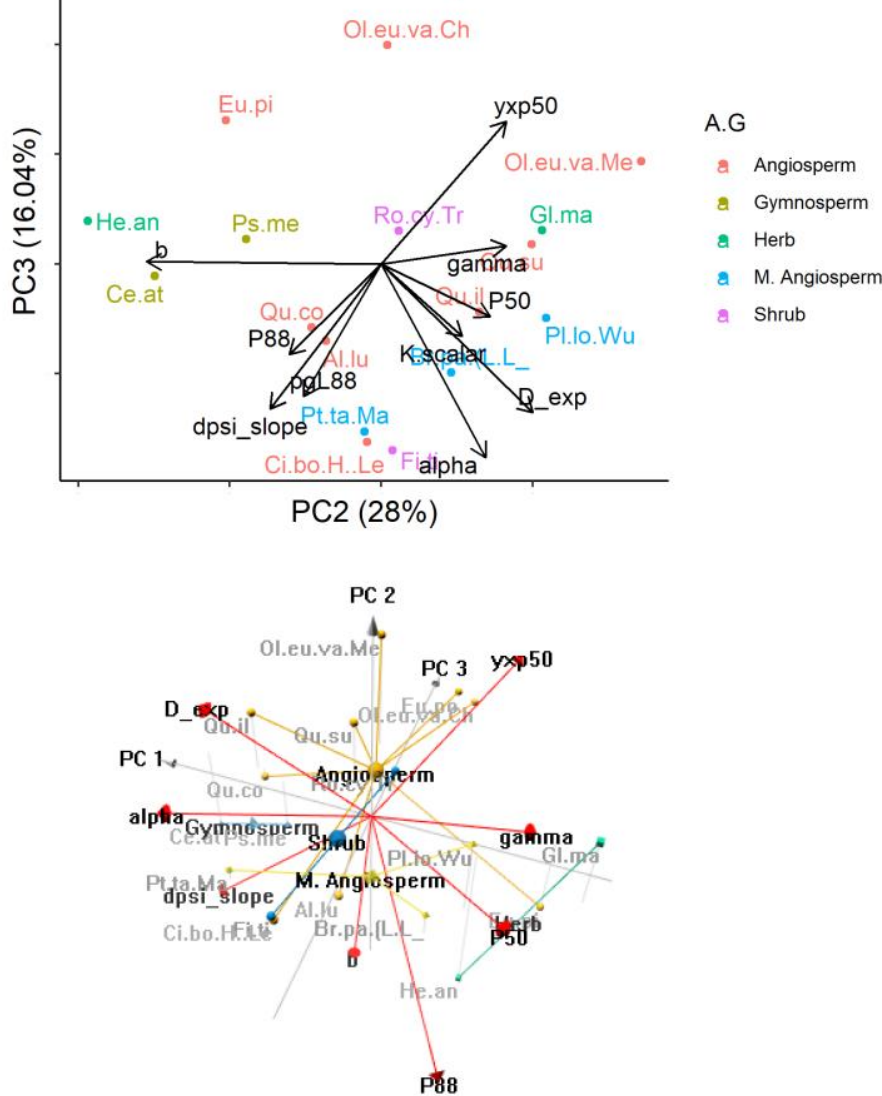

Fig. S10. PCA of fitted traits shows 3 orthogonal axes of variation, captured by $\alpha, \gamma$, and $b$. Three traits explain $85 \%$ of the variation in photosynthetic and hydraulic strategies. 


\section{Cross validation}

\begin{tabular}{|c|c|c|c|c|c|c|}
\hline & Species & $\begin{array}{c}E_{r}(\text { train) } \\
\text { (mean } \pm s d)\end{array}$ & $\begin{array}{c}E_{r} \text { (test) } \\
(\text { mean } \pm s d)\end{array}$ & $\begin{array}{l}E_{r} \text { (train) } \\
\text { (median) }\end{array}$ & $\begin{array}{c}E_{r} \text { (test) } \\
\text { (median) }\end{array}$ & $\begin{array}{c}\text { Number } \\
\text { of data } \\
\text { points }\end{array}$ \\
\hline 1 & Allocasuarina luehmannii & $12.20 \pm 2.20$ & $11.83 \pm 9.88$ & 11.83 & 19.50 & 23 \\
\hline 2 & Broussonetia papyrifera & $101.84 \pm 34.50$ & $112.65 \pm 243.02$ & 112.65 & 163.00 & 12 \\
\hline 3 & Cedrus atlantica & $6.05 \pm 2.41$ & $6.28 \pm 14.54$ & 6.28 & 12.26 & 7 \\
\hline 4 & Cinnamomum bodinieri & $25.40 \pm 4.23$ & $26.57 \pm 180.33$ & 26.57 & 35.67 & 12 \\
\hline 5 & Eucalyptus pilularis & $25.20 \pm 4.74$ & $24.73 \pm 25.38$ & 24.73 & 27.14 & 54 \\
\hline 6 & Eucalyptus populnea & $13.76 \pm 0.87$ & $13.94 \pm 3.15$ & 13.94 & 13.11 & 65 \\
\hline 7 & Ficus tikoua & $4.63 \pm 1.15$ & $4.57 \pm 6.94$ & 4.57 & 6.70 & 16 \\
\hline 8 & Glycine max & $27.01 \pm 8.64$ & $28.61 \pm 111.39$ & 28.61 & 28.66 & 9 \\
\hline 9 & Helianthus annuus & $22.99 \pm 4.90$ & $24.40 \pm 75.56$ & 24.40 & 16.17 & 7 \\
\hline 10 & Olea europaea var. Chemlali & $12.37 \pm 3.36$ & $13.57 \pm 10.76$ & 13.57 & 19.23 & 20 \\
\hline 11 & Olea europaea var. Meski & $9.79 \pm 0.88$ & $10.15 \pm 2.17$ & 10.15 & 11.23 & 10 \\
\hline 12 & Platycarya longipes & $41.24 \pm 8.75$ & $46.23 \pm 112.05$ & 46.23 & 81.58 & 7 \\
\hline 13 & Pseudotzuga menziesii & $9.75 \pm 5.95$ & $12.82 \pm 334.97$ & 12.82 & 12.51 & 10 \\
\hline 14 & Pteroceltis tatarinowii & $39.53 \pm 11.13$ & $41.93 \pm 398.29$ & 41.93 & 45.22 & 12 \\
\hline 15 & Quercus coccifera & $14.03 \pm 6.06$ & $12.37 \pm 217.22$ & 12.37 & 42.94 & 14 \\
\hline 16 & Quercus ilex & $4.85 \pm 1.79$ & $5.55 \pm 38.32$ & 5.55 & 12.08 & 12 \\
\hline 17 & Quercus suber & $2.90 \pm 0.88$ & $2.95 \pm 54.77$ & 2.95 & 10.14 & 5 \\
\hline 18 & Rosa cymosa & $24.39 \pm 3.16$ & $23.90 \pm 17.20$ & 23.90 & 31.97 & 12 \\
\hline
\end{tabular}

Table S1. Cross validation results for each species. We tested the performance of our model using 5 -fold cross-validation. For each species, we divided the data into 5 sets. We performed five training iteration, such that in each iteration, we used one of the five sets for testing and the remaining four for training (estimating parameters). For species with about 5 data points, each set has only one data point, which makes the algorithm equivalent to leave-one-out cross-validation. The mean error $\left(E_{r}\right)$ was comparable in the training and test datasets. However, the standard deviation of the error was higher in the test dataset due to a smaller size of the test dataset. We therefore also compared the median error between the training and test datasets and found the difference to be lesser than the difference in mean error. 